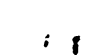

\title{
ÜBER DIE ZWWI ANGEBLICH 1522 AUFGEFÜHRTEN FASTNACHTSSPIELE NIKLAUS MANUELS.
}

Für N. Manuels dichtungen sind neuerdings durch den fund von F.Burg ${ }^{1}$, durch die kritische arbeit von A.Kaiser ${ }^{2}$ ), durch die sprachlich-literarhistorische untersuchung von S. Singer ${ }^{3}$ ), sowie durch die abhandlung von $A$. Fluri über den Totentanz ${ }^{4}$ ) ungeahnte erkenntnisse gew.onnen worden. Der Berner dichter, künstler und staatsmann ist dabei um ein poetisches werk reicher geworden, wogegen seine selbständigkeit im dichterischen schaffen, ja auch die verfasserschaft verschiedener ihm bisher zugeschriebener werke ernstlich in frage gestellt ist. Seine persönlichkeit wird indes wenig verlieren, wenn es sich auch zeigen sollte, dass neben seiner künstlerischen und staatlichen wirksamkeit die dichterische weniger umfassend gewesen wäre, als man bisher annahm, und dass sie wesentlich in der geschickten und glücklichen aneignung und ausgestaltung fremder gedanken bestanden hätte. Er erscheint nur uim so mehr als ein echter sohn seiner bewegten zeit, dessen menschliche erscheinung in ihrer vielseitigkeit und kraft uns verständlicher wird, wenn seine dichtungen vornehmlich als ausfluss der zeitströmungen erscheinen und damit manches von dem dahinfällt, was seine bisherigen herausgeber ${ }^{5}$ ) zum lobe des schaffenden dichters gesagt haben.

1) Dichtungen des Niklaus Manuel: Berner taschenbuch auf 1897, Bern 1896, s. $1-136$.

2) Die fastnachtspiele von der Actio de sponsu, Göttingen 1899. $2,5-13$.

s) Sprache und werke des Niklaus Manuel: Zs. f. hochd. mundarten

4) Niklaus Manuels Totentanz in bild und wort: Berner taschenbuch auf 1901, Bern 1900, s. 119-266.

5) Nach den früheren veröffentlichungen durch Scheurer (1740, benutzt 
Im zusammenhang mit ihrer zeit wollen wir hier die beiden ältesten und bekanntesten fastnachtsspiele Niklaus Manuels betrachten, und werden damit auch zu einer andern datierung wenigstens des einen gelangen, als sie bisher üblich war.

Es gilt als ausgemacht, dass Manuel seine reformatorische tendenzdichtung durch die $\mathrm{zu}$ fastnacht 1522 aufgeführten fastnachtsspiele von den 'Totenfressern' (oder 'Vom papst und seiner priesterschaft') und 'Von papsts und Christi gegensatz', also durch eine doppelaufführung, eröffnet hat oder vielmehr hat eröffnen lassen, da er selbst seit 31. januar auf dem grossen Mailänder zug der französisch gesinnten eidgenossen begriffen war. Auf herrenfastnacht 1522 ist jenes, auf bauernfastnacht 1522 dieses an der kreuzgasse zu Bern öffentlich gespielt worden, so lautet die überlieferung von bald vier jahrhunderten.

Diese datierung unserer beiden spiele, bez. ihrer aufführung, beruht:

1) auf der bekannten stelle von Valerius Anshelms Berner chronik (neue ausg. bd. 4 [1893], 475), wo im anschluss an den handel mit Jörg Brunner, 29. aug. 1522 (s. unten), erzählt wird (wir führen die stelle genau nach der originalhs. Anshelms, bd. 3, 1280 , z. 21 bis 1281, z. 10, an, lediglich mit auflösung der abkürzungen durch cursivschrift):

\section{Spill Euangelifcher fryheit.}

EIs fynd ouch difs jars, zů groffer | fúrḋung Euangelifcher fryheit, | hie zů Bern zwey wolgelertte vnd | jn wyte Land nutzlich vfsgefpreite | Spil; fúrnemlich durch den kúnst | lichen Maler Meifter Niclauffen Ma | nuel gedichtet, $v \underline{n} d$ offenlich an | der krútzgaffen gespilet worden. II Eins namlich der tottenfrårfer ${ }^{1}$ ), berůrend | alle misbrúch des gantzen Babfthůms. | vf der pfaffen vafsnacht. Das ander | von dem gegenfatz des wefens Krifti Jhe/u vnd | fynes genămten Stathalters des Ro̊mfchen Babfts. vf die alten vafsnacht. | Hie zwifchen of der Efchen mitwochen | ward der Ro̊mfch ablas mit dem | bonenlied durch alle gaffen getragen, vnd verfpottet.

bei Wirz, Helv. kirchengesch.; Kuhn, Die reformatoren Berns u. a.) und Schneckenburger (1836): K. Grüneisen, Niklaus Manuel, Leben und werke eines malers und dichters, kriegers; staatsmanns und reformators im 16. jh., Stuttgart und Tübingen 1837, und J, Bächtold, Niklaus Manuel (Bibl. älterer schriftwerke der deutsch. Schweiz, herausg. von J. Bächtold und F. Vetter, 2. bd.), Frauenfeld 1878. Vgl. desselben Gesch. d. deutsch. literatur in der Schweiz s. 282-293.

1) Wir übersetzen: 'das eine, nämlich das der totenfresser' (gen. pl.), d.h. das von den totenfressern - den hohen und niedern geistlichen 
(die letztere erwähnung, vom aschermittwochszug, erscheint bereits, mit der blossen datierung 'nach wenig jahren', zum jahr 1518: 4, 261, hs. bd. 3,905, s. unten);

2) auf der angabe der sämmtlich ohne nennung eines druckorts erschienenen drucke der beiden spiele von 1524 und 1525 - bei Bächtold $\left.\left.\mathrm{B}^{1}\right), \mathrm{C},{ }^{*} 3^{2}\right), \mathrm{A},{ }^{*} 5^{3}$ ), mit ausnahme des letzten

- handelnde, was sowol dem inhalt des stïckes als dem sprachgebrauch Anshelms und dem titel des vermutlich von Manuel gekannten Gengenbachschen gesprächs besser entspricht, als wenn 'Der totenfresser' für nom. sg. und titel genommen wird, wie bereits Scheurer 1, 145. 2, 231 tut; richtig. als gen. scheint es Bächtold cxxxiv aufzufassen. Der zu Biel liegende originale hsl. auszug. Berchtolt Hiallers aus Anshelm (Burg s. 100), wo eins daz totenfressen steht, bietet bereits ein misverständnis der originalhs. Anshelms, wo deutlich Eins namlich der tottenfräffer steht, beide mal mit ausgeschriebenem er (das sonst gewöhulich abgekürzt ist). Auch die abweichung Hallers von seiner vorlage in dem titel des andern spiels: $E$ in gegen fatz deff invitens christi vff den palmtag ze hierufalem, vnd des pabsts viten hat bei der sonst völligen abhängigkeit Hallers von Anshelm kaum mehr gewicht als eine conjectur, und ebenso wird auf die weglassung des fürnemlich, wo von der verfasseischaft die rede ist, kaum viel zu geben sein: diese auslassung bedeutet einfach den ersten schritt auf dem wege, den sodann alle forscher und biographen bis auf Bächtold weiter gegangen sind: den bekannten auf kosten der unbekannten zu bereichern. Die zeitbestimmung lautet hier ebenfalls in disem jar [1522], und für den ablassumzug mit dem bohnenlied vff der escher mittvochen: die tagesbestimmung 'herrenfastnacht' und 'bauernfastnacht' fehlt wol in Hallers auszug nur der kürze wegen. - Der ausdruck 'totenfresser' wird durch andere zeitgenössische bildungen wie kronenfresser, pfründenfresser u. dgl. sowie durch den der alten ausgabe beigegebenen holzschnitt erläutert von Goedeke, Pamphilus Gengenbach s. 619 f. 515. Der titel 'Vom papst und seiner priesterschaft' ist nur aus der überschrift des ersten Zürcher druckes (mai 1524) und seiner nachdrucke entnommen und kann keinerlei autorität beanspruchen, während 'Die totenfresser' der zu Bern noch 1535 umgehende name des stückes ist. 'Tote frelsen' die pfaffen auch in einem gespräch von 1525 bei Schade 176, 35 .

Dass Anshelm oft den gen. pl. auch starker masc. schwach auf -en bildet, spricht nicht gegen die auffassung von der tottenfo: $\delta / f e r$ als gen. pl.; in einer titelangabe konnte er sich wol an die bücherdeutsche form statt an die schweizerdeutsche (-frasseren) halten.

1) Das zweite der von dieser ausgabe rorhandenen exemplare (Maltzahn, Deutscher bücherschatz 1, no. 1071) - ein blosser torso, da es nuir das kleinere spiel (mit alter hsl. nummerierung eines ehemaligen sammelbandes: bl. 504 -511) enthält - befindet sich jetzt auf der Berner stadtbibliothek, in einem sammelbändchen, Rar. 21, das ausserdem enthält: 1) die Narrenbeschwerung 
wahrscheinlich lauter Zürcher Froschauer drucke 1), - ferner des Berner (Apiarius-) druckes von 1540, $\mathrm{E}^{2}$ ), und der undatierten druckortlosen drucke $\mathrm{C}$ und $\mathrm{H}$ (Froschauer druck und nachdruck), wo überall in den titeln gesagt wird:

das eine (grössere) fastnachtsspiel sei zu Bern von bürgerssöhnen

vff der hern fa/snacht inn dem M.D.XXII. iare,

das andere kleinere

vff der alten fa/snacht darnach (im sondertitel ebenfalls: vff der alten Fa/snacht ... im XXij. jar)

öffentlich gemacht worden.

Herrenfastnacht oder pfaffenfastnacht fiel im j. 1522 auf den 2., alte oder bauernfastnacht auf den 9. märz ${ }^{3}$ ), aschermittwoch auf 5. märz.

Statt der angaben der drucke von 1524, 1525, 1540 (sowie $\mathrm{G} \mathrm{H}$ ) hat derjenige von 1529 (D) für die aufführungen nur die datierung: (Bern) in kurtz verschiner zeit - dann aber doch beim zweiten spiel: daselbs vff der alten fasnacht (!) -; der undatierte druck F, die Köln-Wolfenbüttler handschrift (bez. umarbeitung ${ }^{4}$ )) von 1577 und die Hamburgische - diese wol

(Goedeke, Grundr. 1, 90, in der hsl. vorbemerkung dem N. Manuel zugeschrieben, aber wahrscheinlich baslerischen ursprung:s), 2) das Barbeli von N. Manuel (Strassburg, Thiebold Berger), 3) die Totenfresser und Von papsts und Christi gegensatz, gedruckt mai 1524, von N. Manuel (= L, Maltzahn s. 1072. Burg s. 123), worauf 4) abermals unser kleineres spiel folgt. Bl. 504 a holzschnitt von: Růde fogelnest | Clewe pflůg. Bl.511b holzschnitt: Schweizer krieger.

2) Identisch mit C: Burg s. 121.

3) J bei Burg, s. das. s. 121.

1) Nach Bächtold. Bezweifelt von Burg s. 124, da sie bei Rudolphi nicht erwähnt sind.

2) Das ex. der Berner stadtbibl., AD 49 Inc. 396, enthält hsl. einträge von Daniel Mülslin 1720 und von pfarrer Schärer zu Röthenbach 1728, der das büchlein 'in den händen kleiner kinder gefunden' und der stadtbibl. geschenkt hat. Die seiten sind oben in grossen drucklettern nummeriert. [s. XCIr] Berner wappen, rückseite: druckerzeichen des Apiarius.

3) So nach A. Fluri a. a. o. s. 124 (nur steht dort, worauf der verfasser selbst mich brieflich aufmerksam macht, statt 2. märz, 5. märz gedruckt), gegenüber Bächtold xxvinr und cxxx, der den 25. febr. und den 5. märz (sollte wol heissen 4. märz?) als daten ausgerechnet hat.

) Burg s. 129 . 
in folge von verstümmelung, Burg s.1.55 - bieten keinerlei datierung, ebensowenig die undatierten und druckortlosen drucke $\mathrm{K}$ (in Strassburg), L (in Bern, s. anm.) und $M^{1}$ ) (in Berlin, Burg s. $122 \mathrm{f}$.), ausser dass $\mathrm{K}$ die spiele zu Bern vff der Herren Fa/snacht vor ettlichen Jaren und vff der alten Fa/snacht ... vor etlichen jaren ... offentlich gemacht oder gespilt sein lässt.

Der erste Bernische druck mit der bewussten datierung - 1522 für beide fälle — stammt also vom j. 1540. Der nichtschweizerische druck von 1529 tilgt für das grössere spiel diese datierung, die doch, wie in demselben satze die des zweiten (daselbs vff der alten fasnacht) zeigt, in seiner vorlage gestanden hat. Vorhanden ist sie für beide spiele in den Zürcher drucken vom mai und vom august 1524 ( $\mathrm{B} \mathrm{C} * 3$ ) und vom 3. jenner 1525 (A), ebenso in dem druckortlosen 'im jenner' $1525(* 5=J)$. Auf eine solche gedruckte datierung aber hat sich Anshelm, der den bez. abschnitt seiner chronik erst um 1535 schrieb $^{2}$ ), stützen können, wenn ihn damals für die zeit um 1522 sein gedächtnis im stiche liess. Und er hat sich höchstwahrscheinlich darauf gestützt: die mit “den ausgaben wörtlich übereinstimmende fassung der datierungen: vff der hern fa/snacht - Anshelm, der pfaffenfeind, ändert lediglich hern in pfaffen um - und vff der alten fa/snacht hat Anshelm um 1535, wo es noch keinen Berner druck gab, da in Bern vor 1537. keine druckerei bestand, wol einem jener auswärtigen drucke entnommen, wie er ja auch bemerkt, die beiden spiele seien damals 'in weite lande mit erfolg verbreitet' gewesen und weiterhin (a.a.o. z. 17 f.) nachdrücklich widerholt, es sei in dem evangelischen handel kum ein biechle so dik getrukt und so wit gebracht worden, als das diese spiele enthaltende.

Die mithin in bernischen quellen erst 1535, beż. 1540, belegte angabe einer doppelaufführung $\mathrm{zu}$ fastnacht 1522 hat

1) Nach Burg (s. 124, anm.) ist vielleicht dieses M, oder dann G, die von Cysat im j. 1585;86 als neu bezeichnete ausgabe.

2) Anshelm hat, nach vierjähriger abwesenheit von Bern, im j. 1529 den auftrag, seine chronik zu schreiben, erhalten; 1531 schrieb sie sich Berchtolt Haller ab, bis zum j. 1522; die ereignisse von 1524 sind nicht vor 1536 niedergeschrieben (Anshelm, n. ausg. 6, einl. s. XXI f.), kurz vorher also wol die von 1522 und 1523. 
gewis schon beim ersten lesen für jeden, der die beiden stücke und die zeitumstände auch nur ein wenig kennt, etwas befremdliches. Also am 2. märz 1522 wird an der kreuzgasse $z u$ Bern, im belebtesten mittel der alten stadt, zwischen rathaus und leutkirche, wo an der strassenkreuzung der obrigkeitliche gerichtsstuhl steht, ein grosses spiel von fast 2000 versen mit gegen 60 sprechenden und vielen hundert stummen personen aufgeführt; am 9. märz darauf gibt es ebenda eine kleine pantomime, d.h. einen doppelten aufzug stummer personen mit musik, wozu zwei bauern ihre 'sprüche' von zusammen rund 200 (in der ältern fassung, derjenigen der Hamburger hs., bloss etwa 150) versen halten - beides von demselben verfasser oder hauptverfasser, der beide male landesabwesend ist. In dem stücke zur herrenfastnacht tritt das ganze geistliche und päpstliche wesen mit all seinen misständen und irrlehren in langen reden und gegenreden auf; acht tage später begnügt sich derselbe dichter und wol auch dieselbe truppe mit den derben ausfällen zweier bauern gegen einige wenige päpstliche und kirchliche misbräuche. Während hier, in dem stück vom 9. märz, zwei ländliche rüpel lediglich auf das weltliche und kriegerische leben des papstes und sodann auf ablässse und wallfahrten schimpfen, wird dort, bei der aufführung vom 2. märz, der kirche und klerisei durch ihre eigenen vertreter vor dem beifalljauchzenden volke das ganze klagenrepertorium und sündenregister des reformationszeitalters vorgeführt: ihre betrügereien durch die lehren vom fegefeuer, vom cölibat, von der schlüsselgewalt, von den geistlichen rechten, von almosen und heiltümern, ihre verachtung des göttlichen und ihre verehrung des blossen menschenwortes, insbesondere aber der einträgliche misbrauch, den die kirche mit den totenmessen und mit den übertretungen des keuschheitşgelübdes der geistlichen treibt.

Isi gegenüber dieser gesalzenen und gepfefferten predigt, die an der herrenfastnacht grösstenteils die mitglieder der geistlichkeit selbst sich selber halten, das bauerngespräch $\mathbf{z u}$ dem festzug der bauernfastnacht desselben jahres nicht tatsächlich senf nach der mahlzeit? Ist, es Manuel oder den andern Berner reformfreunden zuzutrauen, dass sie in so unkünst- 
lerischer und abschwächender weise 'den bauern auf den herrn gesetzt' hätten?

Und das in den märztagen 1522, da in Zürich eben erst durch einige übertreter der fastengebote Zwingli zur eröffnung des kampfes mit der geistlichen obrigkeit veranlasst wird ${ }^{1}$ ), während in Bern Berchtolt Haller erst im november desselben jahres 'unter hintansetzung päpstlicher und bischöflicher ordnung' entschieden mit der evangelischen predigt hervortrat ${ }^{2}$ ) und es inzwischen für die feinde des papsttums jedenfalls auch beim scherz die schritte zu wägen galt?

Nun hat man schon lange bemerkt, dass das spiel von der herrenfastnacht, 'Vom papst und seiner priesterschaft', bei Anshelm 'Der totenfresser' betitelt - wir wollen es im folgenden der kürze wegen einfach das 'grössere' spiel nennen im gegensatz zu dem angeblich gleichzeitig entstandenen 'kleineren' spiel, dem bauernfastnachtsspiel 'Von papsts und Christi gegensatz' - also man hat längst bemerkt, dass das grössere spiel in allen vorhandenen drucken begebenheiten als geschehen voraussetzt, die in die zeit nach fastnacht 1522 fallen. Da tritt schon ziemlich im anfang (Bächt. v. $175 \mathrm{ff}$.), wo nach dem einleitenden leichenzuge die hohen geistlichen die einträglichkeit der totenmessen und der sonstigen kirchlichen einrichtungen preisen, gleich hinter dem papst, dem cardinal und dem bischof, der 'vicari, Joannes Fabler' auf: er beklagt sich, bauern und laien hätten mit hilfe der bibel und der buchdrucker ihm scharf zugesetzt - ihm den gyren gnaw berupft -; da er als redner seines bischofs von fremden inseln und landen gesprochen, sei er von groben schlechten handwerksleuten mit der heiligen schrift wie im bade gebürstet und ausgerieben worden. Fabler ist natürlich der bischöflich Constanzische generalvicar Johannes Faber (Schmid, eigentlich Heigerlin, Heierli), der nach dem ersten Zürcher religionsgespräch unterm 10. märz 1523 eine 'Underrichtung' hatte erscheinen lassen, worin er sich rechtfertigte, dass er in Zürich von Kreta, India u. a. gesprochen, und dessen schrift in dem 'Gyrenrupfen' etlicher Zürcher bürger unter dem datum des 1. september 1523 übel zerzaust worden

1) Wirz, Helv. kirchengesch. 4, 1, $207 \mathrm{ff}$. Stähelin, Zwingli 1, $203 \mathrm{ff}$.

2) Anshelm 4, 470. Wirz 4, 2, 380. 
war. - Da kommt ferner in unserm grössern stück (864 ff.) vor den päpstlichen thron ein Rhodiser ritter mit verhängtem zügel angesprengt und bittet im namen seines ordensmeisters, der papst möchte zur hilfe gegen die Türken, die seit mitte august Rhodus mit kugeln von zehn spanmen umfang beschössen, das für den Türkenzug gesammelte geld verwenden. Die beschiessung von Rhodus durch die Türken geschah tatsächlich seit dem 28. juli 1522 mit kugeln von bisher unerhörter grösse und endete mit der übergabe am 25. december 1522.1) Diese stelle kann also nicht vor herbst 1522 geschrieben, bez. in unsere drucktexte von $1524 \mathrm{ff}$. hineingekommen sein, die über die Zürcher disputation und das Gyrenrupfen nicht vor herbst 1523. In der tat fehlt diese letztere stelle auch noch in der Hamburger hs., die nach Burg eine zwischenstufe zwischen der aufgeführten und der gedruckten fassung darstellt. ${ }^{2}$ ) Dagegen ist die belagerung von Rhodus, die auch in dieser hs. nicht fehlt, ein unentbehrlicher bestandteil des ganzen stückes, und wir können uns das spiel vom märz 1522 ohne diesen Rhodiser ritter vom august oder september $1522^{3}$ ) gar nicht denken. Denn die bisherige annahme, das stïck sei damals ohne die scene mit dem Rhodiser gespielt und diese sei erst für die druckbearbeitung hinzugedichtet worden - eine annahme, die allerdings für die andere stelle, die von Faber, zutrifft ergibt sich aus einer übersicht des ganzen spiels als unhaltbar. Diese scene billdet geradezu das rückgrat des stïckes. Wenn wir auch von einer dramatischen handlung im heutigen sinne nicht sprechen können, so zeigt doch das spiel eine deutliche gliederung. Die trostlose schilderung des verkommenen kirchenwesens, die von im ganzen 1945 versen rund (mit abzug der

1) Schlosser, Weltgeschichte 12, 115 .

${ }^{2}$ ). In dieser ursprünglicheren fassung ist denn auch der gute anschluss von (Bächt.) 211 (Hochwirdiger fürst und gnädiger herr als anrede des bischofs, nicht Fablers) an 174 (rede des bischofs) erhalten, der in den drucken durch einschiebung der rede Fablers unverständig zerstört ist.

3) Wenn der ritter 901 sagt: Die zit sid mitten ougsten har [1522, wo die belagerung begann] Die dunkt uns lenger denn ein jar, so dürfen wir kaum mit Burg s.130 daraus herauslesen, dass die stelle unbedingt vor august 1523 gedichtet sei, sonst müisste doch auch wol" der fall von Rhodus (dec. 1522) erwähnt sein, während es nach $1517 \mathrm{ff}$. offenbar noch aufrecht steht. Aber einige zeit seit dem beginn der belagerung ist sicher bereits verflossen. 
spätern zusätze) 750 einnimmt, wird mit dem kommen des ritters unterbrochen durch den einzigen tatsächlichen vorgang des stückes, die von papst und kaiser verschuldete bedrängnis von Rhodus. Aber die gehoffte wendung tritt nicht ein. Die klagen der bauern, sogar die strafreden der apostelfürsten bleiben ohne eindruck; der papst rüstet sich zu neuen kriegszügen, aber gegen christen und nicht gegen die Türken, wie dies der prädicant in einem schlussgebet beklagt, das gegenüber dem teuflischen verderben der kirche von Christus allein die rettung erhofft.

Das spiel lässt sich in sieben einzelne auftritte zerlegen:

I. (Bächt. 1-752, mit abzug von 175-210. 437-494. 737 -750 u. a., was bei Burg noch fehlt). Die totenmessen und die päpstliche hierarchie (die scene ist wie alle späteren am päpstlichen hofe gedacht; ihre sämmtlichen personen sind von anfang an auf der bühne anwesend; auch die beiden apostel des fünften auftritts erscheinen bereits als zuschauer im hintergrunde $\left.{ }^{1}\right)$ ). Bei gelegenheit des leichenbegängnisses eines reichen bauern, den die leidmänner beklagen, triumphiert der kilchherr mit messner [sigrist], metze und tischdiener über die einträglichkeit der totenmessen und jahrzeiten. Ebenso der auf dem throne sitzende papst, der hierdurch, sowie durch die schlüsselgewalt und die geistlichen rechte, durch ablass und fegefeuer, zu macht und reichtum gekommen ist. Cardinal, 'bylsdschaf' [bischof], propst und decan stimmen ihm bei und preisen das gute leben, das sie mit krieg, jagd und jeglicher hoffart, dem evangelium zuwider, aber des papstes lehre gemäss, führen; der pfarrherr mit metze und caplan, der abt und der prior sammt dem schaffner, der junge mönch, die nonne, die begine und der nollbruder [diese beiden in den drucken umgestellt] spüren dagegen bereits den neuen evangelischen geist im volke und die daherige abnahme ihrer einkünfte, und sind auch teilweise selbst mit ihrem stand zerfallen [dem der mönch flucht] oder

1) Scenarische bemerkung zu anfang [nur in den drucken, da der anfang der hs. fehlt]. - Im folgenden sind die wesentlichsten abweichungen der drucke (bez. des textes bei Bächtold) von dem Hamburger text in [] vermerkt. Jene geben überdies den sprechenden personen noch eigennamen bei, die in dem Hamburger text, mit ausnahme derjenigen der gardescene (II) und derjenigen des doctors oder prädicanten, noch fehlen. 
nützen ihn $\mathrm{zu}$ zweifelhaftem gewerbe aus [als weitere geistliche personen sind später - noch nicht in der Hamburger hs. - hinter dem bischof der vicari Fabler und hinter dem abt und schaffner der quästionierer Bonaventura Giler, s. unten, eingeschoben]. Von laien treten sodann auf: der landfahrer, der mit seinen pilgergängen auf 'St. Jacobs' strasse' bei den bauern keine unterstützung mehr findet, der kranke hausarme, dem die pfaffen, mönche und nonnen das almosen vorwegnehmen [und der sich nur des himmelreichs tröstet, das den armen verheissen ist], endlich der edelmann, dessen vorfahren ihr gut den pfaffen und mönchen gegeben haben und dessen kinder nun darben müssen, ohne dass ihnen der wolfsgesang der priester hilft [die mit dem fegefeuer sich bereichert haben].

II. (Bächt. 753-863). Die päpstliche garde. Der gardehauptmann sowie die gardeknechte Hans Eberzahn [Zahn], Heini Ankennapf, Ludi Kräuterziger [Benedict Löwenziger] und Dies [Durs] Kalbskopf preisen den papst, der sie aus den frommen spenden der bauern auf kosten der armen reich besoldet und der dem Heini, welcher die kriegsmetze Sibylla Zöppli [hure Sibylla Schieläugli] mit sich führt, sowie dem Dies, einträgliche pfründen und chorherrenstellen gegeben hat, während Ludi ein reicher dorfpfaffe zu werden hofft. Auch der 'schryber' hält auf den papst, dessen geldquellen so mannigfaltig sind, mehr als auf Christus und Petrus.

III. (Bächt. 864-1083). Rhodiser-scene. Von einem posten und dem gardehauptmann eingeführt, erscheint ein Rhodiser ritter und meldet dem papst, wie seit mitte august die Türken Rhodus beschössen, wie sie es einnehmen und sodann Apulien angreifen würden, sofern nicht der papst, der so viel geld für den Türkenzug gesammelt, hilfe bringen werde. Aber dieser, der andere kriege zu führen hat, hat für Rhodus keinen heller übrig. $\left.{ }^{1}\right)$ Der ritter muss mit leeren händen nach Rhodus heimkehren, um dort zu sterben, und ruft auf den papst die himmlische rache herab, die dem antichrist angedroht ist; der Türke aber, auf der scene erscheinend, spottet

1) Von hier an bis gegen die mitte der apostelscene (V) geht die grosse lücke der Hamburger hs., Burg s. 38/39. 
der christenheit, die bereits zu drei vierteilen sein ist und es bald ganz sein wird.

IV. (Bächt. 1084-1387). Bauern-scene. Der doctor Lüpolt [d. L. predicant; später, vor v. 1834, in beiden fassungen: doctor Lüpolt ${ }^{1}$ ) Schüchnit] flucht dem papst, der, indem er Rhodus preisgibt, sich unwürdig zeigt, auch nur der geringste sauhirt auf erden $\mathrm{zu}$ sein, und fragt die herankommenden bauern, ob auch sie von seiner schinderei wüssten. Ihrer sieben treten auf und beklagen sich zunächst über den betrug, der seinerzeit mit dem ablass in der frauencapelle des chors der kirche zu Bern durch den grauen mönch und herrn Heinrich Wölfli getrieben worden ist. Gegen sechshundert jahre lang löse man den ablass, der doch immer noch von der kirche versetzt sei. Diese stütze sich auf die concilien und habe doch einst eine hure zum papst gehabt. Christus habe der obrigkeit gesteuert, nicht den pfaffen, und den armen hirten, bauern und laien sei er zuerst verkündet worden. Die ablasskrämer, die Christi heil um geld verkauft und gott zu einem krämer gemacht hätten, seien schlimmer als diebe; man sollte sie alle ertränken.

V. (Bächt. 1466 2)-1761). A postel-scene. Petrus konmt mit Paulus aus dem hintergrund, und nachdem er den papst lange durch eine brille betrachtet hat, fragt er einen curtisan, wer der mann sei, den man da wie einen Türken oder heiden auf den achseln trage. Jener wundert sich der frage von seiten des Petrus und nennt den papst den herrn ungezählter fürstentümer, die er, der statthalter Petri, als dessen erbteil besitzen will. Petrus kann sich nicht erinnern, je nach Rom gekommen $\mathrm{zu}$ sein; er ist ein armer fischer gewesen und kennt

1) Die erklärung Burgs s. 100: Lupolt $=$ Lup(priester Bercht)olt ist ansprechend, obwol vieles in L.'s reden, sowie der doctortitel, auch auf Sebastian Meyer hinweisen könnten.

2) Die in allen drucken hier voraufgehende stelle 1388-1465 (kriegerische reden der fünf verschiedenen päpstlichen hauptleute und des papstes) gehört sicher nicht hierher, sondern hinter die kriegerischen reden des papstes, des cardinals und des päpstlichen geschützhauptmanns 1762-1801, an die sie in der Hamburger hs. (Burg s. 48,1 - 51, 21) ganz richtig (und mit voraussstellung der rede des reisigenhauptmanns, Bächt. 1444-1451) anschliessen. 
weder jenen noch sein gesinde. Der curtisan aber, der den alten für gedächtnisschwach hält, belehrt ihn über die macht des papstes, den man mehr fürchtet als den kaiser und als gott selbst und der für geld den himmel zu kaufen gibt; Petrus solle sich nur vor seinem banne hüten. Dieser entsetzt sich über den frevel an gott, den sein angeblicher statthalter begeht; Christus ${ }^{1)}$ allein könne uns selig machen. Auch von der schlüsselgewalt, die man, der auskunft des curtisans zufolge, ihm, dem apostel, zuschreibt, weiss er nichts; die schlüssel zum himmel besitzen alle christen zumal. Er fragt nun den Paulus, was er von dieser auskunft des 'pfäffleins' halte, und ob er, Petrus, sich wirklich so weit habe vergessen können, als nachfolger Christi, der ihm einst die füsse gewaschen, der oberste unter allen christen sein zu wollen. Aber Paulus kennt den papst auch nicht; täte er die werke Petri und Christi, so könnte man ihm wol seine ansprüche hingehen lassen. Doch Petrus weiss nichts davon, dass der papst je gepredigt oder sich der armen angenommen hat, und die beiden sind darüber einig, dass er geradezu das widerspiel Christi sei. Sie wollen mit ihm nichts zu tun haben; gott, der keine frühmesse verschläft, wird diese gottesschmach nicht ungestraft lassen.

VI. (Bächt. 1762-1801. 1444-1451. 1388-1443. 14521465. [1802-1833]). Musterungs-scene. Der papst beruft die cardinäle zum kriegsrat und ordnet [unbekümmert um die gewalttaten, die jetzt zu Rhodus geschehen mögen] sein heer zum krieg, wofür er aufs frühjahr einen ablass in deutsche lande ausschreiben will. Ein cardinal begrüsst freudig diese aussichten. Es marschieren auf: der geschützhauptmann mit einem mächtigen geschwader [400 geschwadern], der hauptmann der reisigen mit 200 [400] glenen, der hauptmann der stratioten mit 400 [300] mann, die in zehn jahren nie anders als im feld gelegen haben, der hauptmann der pellkaner [Italianer], der dem papst vor langen jahren zu Ravenna, Rimini, Pistoja und in der Venediger schlacht gedient hat, der hauptmann der eidgenossen, die vor langer zeit schon für ihn gegen die Türken auf der Tiber [fehlt in den drucken ${ }^{2}$ )] ge-

1) Hier setzt die Hamburger hs. wieder ein, Burg s. 39.

2) In der nachträglichen tilgung dieser stelle vermutet Burg s. 131 
stritten haben, endlich der hauptmann der landsknechte, der ihm mit kräftigen flüchen sechshundert alte kriegskatzen mit zerschnittenen knebelbärten zuführt. Der papst heisst seine kriegsleute willkommen und will ihnen einen cardinal schicken, der sie mustert und bezahlt; er gibt ihnen banner und zeichen und heisst sie sich mit wein füllen; der bauer, der die schuhe mit weidenruten bindet, muss ihn . bezahlen. [Der oberste hauptmann, cardinal de Sancte Unfrid, führt das 80000 mann starke heer $\mathrm{ab}$, von dem er einen katalog gibt: 500 glene zu ross, 1000 ertschiere, 4000 leichte pferde, 20000 deutsche und 25000 welsche fussknechte, 38 kartaunen, 22 schlangen nebst anderem geschütz, 800 bauern mit schaufeln. Der papst entlässt das heer mit seinem ségen.]

VII. (Bächt. 1834-1945). Gebet des doctors [Lüpolt Schïchnit]. Herr Jesu Christ, lass uns alle menschenlehre verachten und an deine erlösung und an dein evangelium uns halten statt an des papstes acht und bann und an die zeugnisse der heiden! Könnte ich mit einer axt auf éinen streich die päpstlichen rechte zerscheiten! Das hiesse wahrhaft wider den Türken gestritten. Herr, lass uns auf dich und nicht auf jenen sterblichen madensack vertrauen und verleih uns deinen göttlichen segen!

Man sieht: die Rhodiser scene (III) steht im mittelpunkt des ganzen. Von der schilderung der auf dem totenmessenunfug aufgebauten päpstlichen hierarchie (I) führt die kriegerische gardescene (II), die in den eingangsworten (753 ff.) an jene misbräuche anknüpft, hinüber zum auftreten des Rhodisers (III), der die Türkennot schildert, aber vom papste abgewiesen wird; die klage über die Türkengefahr und die härte des papstes in der rede des doctors leitet die bauernscene (IV), der türkische oder heidnische aufzug des papstes und seine gegen christen gerichteten feldzüge die apostelscene (V) ein;

die berichtigung eines geschichtlichen irrtums. Vielleicht hat bei dem Zürcher drucker zugleich eine kleine kritische eifersucht auf Bern und dessen Cronicken mitgewirkt: der in den fünfziger oder sechziger jahren des 15.jh.'s von dem Berner pfarrer Eulogius Kiburger geschriebene tractat 'Vom herkommen der Schwyzer und Oberhasler' (Bächtold, Die Stretlinger chronik LXXXI. $179 \mathrm{f}$. $185 \mathrm{ff}$.) ist offenbar hier von Manuel gemeint und benutzt. 
die musterungsscene (VI) ist (wenigstens in den drucken, 1769 -1773) motiviert mit der gleichgiltigkeit des papstes wegen Rhodus und bildet jedenfalls für den hörer ein ironisches gegenstück dazu; endlich das gebet des doctors (VII) sieht in der vernichtung der päpstlichen rechte den wahren krieg gegen den Türken. Wol ist das ganze stück sehr lose aufgebaut und wirkte wol hauptsächlich durch die verschiedenen teilweise glänzenden aufzüge, die lediglich von dem gedanken der entartung des papsttums zusammengehalten sind, und durch die damit contrastierenden bauern- und apostelgespräche; auch ist nicht bloss die eine und andere stelle sicher erst nachträglich eingesetzt, sondern auch die eine oder andere scene könnte später zugedichtet sein und bei der ersten aufführung noch gefehlt haben: die Rhodiser scene aber sammt den nachfolgenden beziehungen auf den Türken hat so sicher zum ursprünglichen stück gehört wie die apfelschussscene zu jedem Tellenspiel. Sie kann nicht vor dem spätjahr 1522 gedichtet sein; folglich ist auch das ganze stück Manuels unmöglich zu fastnacht 1522 aufgeführt worden.

Diese datierung hat Anshelm bei bereits irrendem gedächtnis aus einem der Zürcher drucke von $1524 \mathrm{ff}$. entnommen, der hierüber falsch berichtet war und in ziemlich unsorgfältiger weise, jedenfalls ohne mitwirkung, wahrscheinlich ohne ermächtigung Manuels erstellt worden ist. Denn der verfasser des stückes hätte eine so den zusammenhang störende einschiebung wie die zwischen der rede des bischofs und dessen anrede durch den papst vorgenommene (obèn s. 87, anm. 2), niemals begehen können, eine einschiebung zudem, worin von Zürcherischen ereignissen und druckschriften des jahres 1523 in einer bei einem volksmässigen Berner fastnachtsspiel undenkbaren weitläufigkeit die rede ist. Er hätte namentlich niemals die ganze reihe von reden päpstlicher hauptleute und des papstes 1388-1465 so ganz an falsche stelle geraten lassen, wie dies in den drucken von 1524 und danach in allen folgenden geschehen ist (oben s. 90, anm. 2). Er hätte gewis auch, wenn er den anfänglich meist nur als typen ihrer stände benannten personen die bühnennamen der drucke gegeben hätte, nicht die anfangs namenlos auftretende Pfaffenmatz 35 ff. und 289 ff. mit zwei verschiedenen namen (Anastasia Fuchsörli, Lucia Schnäbeli) eingeführt und 
ihren 7ilchherrn oder $p$ farrer, der doch wol alle drei mal (16 ff. 27 ff. 259 ff.) dieselbe person ist, zuerst Herr Ruprecht Meeher und dann Mattern Wetterleich benamset.

Man könnte wol, um die Anshelmische datierung wenigstens für einen teil unseres stückes zu retten, auch annehmen, dieses sei aus einem in seinen echten teilen auf fastnacht 1522 verfassten kleinern spiel von den totenfressern entstanden, das unserer ersten scene entsprach, aber einen andern schluss hatte, und an dieses spiel seien dann beim druck ein oder mebrere ursprünglich ebenfalls selbständige spiele angeschoben worden. In der tat kann man sich z. b. die (noch in den drucken in besonders guten : versen verlaufende) apostelscene (V, Bächt. 1466-1761, bez. Burg s. 46,9) recht wol, verbunden mit einem pantomimischen aufzug des papstes, als ein solches besonderes spiel in der art desjenigen von papsts und Christi gegensatz denken. Ferner könnte in ganz ähnlicher weise die bauernscene (etwa von 1110-1387) ein eigenes bauerngespräch vom ablass mit dem aufzug eines ablasskrämers gewesen sein ${ }^{1}$ ) und man dürfte vielleicht sogar die bestimmte zweimalige angabe Anshelms von einem spiel und umzug mit dem ablass (dass hiezwischen - zwischen dem spiel auf herren- und dem auf bauernfastnacht - uf der Aeschen mitwochen der Romsch ablas mit dem bonenlied durch alle gassen getragen und verspotet worden ${ }^{2}$ )), auf einen an dieses bauernspiel sich anschliessenden

1) Von den sieben bauern, deren reden den text dieses spiels bilden würden, tragen (in den drucken, während in der hs. die ganze scene in die lücke fällt) fünf ganz ähnliche ihre hantierung und kleidung bezeichnende namen, wie die beiden des kleineren spiels von 1522 sie in den drucken führen (Rúde Vogelnest, Cläywe Pflig), nämlich Nickli Zettmist, Riffi Pflegel, Heini Filzhiot, Zenz (=Vincentius, kirchenheiliger von Bern) Klepfgeisel, Batt (= Beatus, patron des Oberlandes) Süruschmer, wogegen zweie als Amman von Hanfdorf und Amman von Maraschwil bezeichnet sind: vielleicht liegen darin bestimmte anspielungen, wie auch mit dem Cläwy Stromáyer und dem Ridy Gamper der hsl. form des kleineren spiels bestimmte persönlichkeiten gemeint sein könnten.

2) Oder, wie er sich zum j. 1518 (n. ausg. 4, 261. hs. 3, 905, z. 10-14) ausdrückt: Aber nach wenig jaren [nach 1518] ward v/s dim | Ablas, vnd lynen brieffen vff der $a / c h$ en|mitwoch ein offen va/snacht|/pyil, vnd mit. dem Bonen lied durch alle | gaffen getragen, vnd difss ift zi Bern, | durchs Euangelifch liecht, de/s |R[8m/chen]. ablas lectze, vnd ouch, das Got | gdb, end gewe/en. 
höhnischen umzug mit verspottung von ablassbriefen beziehen, wobei dann für ein kurzes totenfresserspiel das aufführungsdatum von herrenfastnacht 1522 bestehen bleiben könnte. Aber die überlieferung ist zu schlecht, bez. in der hs. zu lückenhaft, als dass wir mit sicherheit ein solches kürzeres totenfresserspiel von 1522 annehmen oder gar herstellen dürften. Sodann spricht Anshelm, der 1522 und 1523 in Bern wohnte, mit aller bestimmtheit - und wahrscheinlich auf grund des Zürcher drucks, den er gesehen hatte - von $z w e i$ spielen nebst einem umzug, wovon das erste spiel, das von den totenfressern, 'alle misbräuche des ganzen papsttums' behandelt habe: in der totenmessenscene (I) ist aber z. b. von der kriegslust des papstes noch nicht, sondern nur kurz von der des cardinals die rede. Ferner scheint uns der aufbau unseres stückes als eines ganzen doch (s. oben s. 87 und 92 f.) ein leidlich einheitlicher, um éin ereignis herum gruppierter; eine zusammenschweissung verschiedener spiele von 1522 und $1523 \mathrm{zu}$ einem einzigen, mit einer datierung im titel, die ausserdem als teilweise unrichtig von Bernischer seite hätte beanstandet werden können, dünkt uns für einen Zürcher druck vom mai 1524 auch nicht glaublich; wir werden das grössere stück jedenfalls als ein dem Hamburger schreiber und dem Zürcher drucker vorliegendes einheitliches und in Bern zusammen aufgeführtes $\mathrm{zu}$ betrachten haben. Innerhalb dieses spiels aber, und sogar innerhalb der totenfresserscene (I), glauben wir nun, abgesehen von der offenbaren zutat von 1523 über Faber, sowie von der Rhodiserscene, sehr deutliche spuren von Berner und schweizerischen begebenheiten aus dem verlaufe des jahres $1522 \mathrm{zu}$ erblicken, die es schlechterdings nicht erlauben, die datierung Anshelms für unser spiel oder auch nur für einen teil desselben festzuhalten.

Schon Bächtold hat, ohne seinerseits eine folgerung daran zu knüpfen, in v. 445-449, wo die bauern den klosterbettler, der sich 'Unser frauen bruder' nennt, spottend zu seiner reichen schwester weisen, eine anspielung auf einen handel vom j. 1523 erblickt. Die gattin des chronisten Anshelm hatte bei einer badefahrt gesprächsweise behauptet, unsere liebe frau sei eine frau wie sie auch; der gatte ward deshalb, wie er selbst (n. ausg. 5, 26) erzählt, gebüsst (25. nov. 1523) und (6. jan. 
1524) an seiner besoldung gekürzt, und die fehlbare behielt den namen Unser frauen schwester. Freilich steht die anspielung auf diese geschichte in der rede des quästionierers, den wir schon aus seinem fehlen in der Hamburger hs. als erst in die drucke eingeschoben erkannt haben und dessen einführung sicher mit misbräuchen zusammenhängt, die sodann durch einen ratsbeschluss vom spätjahr 1524 abgestellt wurden. 1)

Aber einige andere händel des bereits reformatorisch sehr bewegten jahres 1522 sehen wir in unserm stücke, und zwar auch schon in seinen unzweifelhaft echten teilen, sich abspiegeln: den process des Jörg Brunner zü Bern september 1522, ferner die bittschriften $\mathrm{Zwinglis}$ und den handel des Urban Wy Is wegen der priesterehe, juli bis november 1522, endlich den commentar Sebastian Meyers von Bern zum hirtenbrief des bischofs von Constanz, spätjahr 1522.

Des Brunner-processes vom august und september 1522 gedenkt Anshelm (4;471-474) unmittelbar v o r der erwähnung der angeblich im märz 1522 zusammen aufgeführten beiden spiele Manuels. Wir kennen den handel genauer aus einem von der hand Berchtolt Hallers mit einleitung, schluss und

1) Teutsch Missiven-Buch $P$ 301 b; 1524, samstag nach Otmari (mir durch herrn staatsarchivar dr. Türler nachgewiesen). Abdruck in v. Stürler, Urkunden der Bernischen kirchenreform 1, $127 \mathrm{f}$. und in B. Haller, Aus den Bernischen ratsmanualen 1,191. Schultheiss und rat vernehmen, wie die que/tionierer und der klsfter vnd kilchen bettler die leute überlaufen, und zwar mit empfehlung [? das wort fehlt in der hs.] der päpste und bischöfe, die dafür besondern ablass verheissen. Der rat ist der ansicht, das folich ir usgeben gelt vnd git weder nutz noch frucht bringt vnd daby ouch der applas, fo finen vr/prung allein us dem liden Chrifti hat, nit verkoufft fol werden. Es wird daher befohlen, solche questionierer und bettler abzuweisen (fürer zi wi/en). und ihnen weder in noch ausser den kirchen station oder aufenthalt zu gewähren. Zugelassen sollen nur sein die boten und questionierer der barfüsser, der prediger, der heiliggeister und der frauen in der insel zu Bern, ferner die von dem gotteshaus St. Bernhart (GrossSt. Bernhard) und von Ruffach, wenn sie brief und siegel der obern v.orweisen. - Zum nov. 1522 ist der hsl. Simlerschen sammlung in Zürich eine druckschrift 'Geben zů Pfortzen am erften Tag des Chriftmonat ... M.D.XXij. Jar' eingeheftet, mit der hsl. bemerkung E/t Era/mj Fabritij [s. unten] und der überschrift Ermanung zü den Que/tionieren ab zustellen überflüffigen kosten. Als verf. nenut sich im eingang Joannes Schamblin. 
bemerkungen versehenen und durch das eigenhändige zeugnis Brunners selbst als zuverlässig bestätigten ${ }^{1}$ ) berichte im Zürcherischen kirchenarchiv (staatsarchiv E. 2, 3460-3470), wovon die hsl. sammlung Simlers der Zürcher stadtbibliothek (S. mscr. 6) eine abschrift Simlers selbst, J.J. Simlers Sammlung alter und neuer urkunden zur beleqchtung der kirchengeschichte (1758) 1, 2, 461-492 einen abdruck, das Berner staatsarchiv in Zehenders Kirchengeschichten der stadt und republik Bern (c. 1730) 1, 39-60 abermals eine abschrift bieten. ${ }^{2}$ )

Jörg Brunner von Landsberg in Baiern, helfer des pfarrers und decans von Münsingen, ward im frühsommer 1522 vom rat zum pfarrer der nahen wallfahrtskirche Klein-Hönstetten (jetzt bauernhaus Kleinhöchstetten) gewählt; sein vorgänger Hans Wacker war wegen seiner reden über totengebräuche abgesetzt worden: er hatte gesagt, wer für die in Mailand (wol an der Bicocca 27. april 1522) umgekommenen Schweizer bete, begehe die sünde gegen den heiligen geist. ${ }^{3}$ ) Brunner hatte schon zu Münsingen in einer predigt vom sonntag Cantate den papst den wahren antichrist genannt. Der grosse zulauf, den er nun als pfarrer in Klein-Höchstetten hatte, veranlasste seinen decan, mit vier anderen pfarrern über Brunners predigten beim rate von Bern klage $\mathrm{zu}$ führen und ihn $\mathrm{zu}$ bitten, er möchte Brunnern versetzen und dessen präsentation beim bischof verschieben. Er erwirkte ferner einen befehl des bischofs, demgemäss Brunner unverzüglich nach Constanz geschickt werden sollte. Der rat aber veranstaltete mit beschluss vom 27. juni eine eigene untersuchung durch eine commission, die, aus sieben geistlichen und sieben weltlichen mitgliedern bestehend, am 29. august 1522 im Barfüsserkloster, wo der

1) Que hic fcripta funt, proteftor ego Georgius minifter verbi dei in Cleinen Hech/tetten omnia fic acta effe. Simler s. $461 \mathrm{f}$. Zürcher staatsarchiv E. II. 341, s. 3460.

2) Vgl. (Scheurer) Bernerisches Mausoleum ... von einem der SchweizeriSCHen Theologen (Prof. Samuel Scheurer, 1740) 1, 150-164. Wirz, Helvet. kirchengeschichte (1814) 4, 2, 402-415. Kuhn, Die reformatoren Berns (1828) s. 249-272. F.Studer im Berner taschenbuch auf 1885, s. 224 -250. Die bez. regierungserlasse bei Stürler, Urkunden z. bern. kirchenreform s. $5 \mathrm{f}$. $94 \mathrm{ff}$ : $103 \mathrm{f}$.

3) Anshelm 4, 472. Scheurer s. 153; bei Haller, Simler und Zehender noch fehlend.

Beiträge zur geschichte der deutschen sprache. $\mathrm{XX} 1 \mathrm{X}$. 
reformfreund dr. Sebastian Meyer als lesemeister wohnte, im beisein einer menge von zuhörern geistlichen und weltlichen standes die klage und verantwortung entgegennahm. Als erster klagepunkt wird aufgeführt und von Brunner verteidigt sein ausspruch: der papst, die cardinäle und die bischöfe seien teufel und wahre antichristen; die priester und mönche, die es mit ihnen hielten, seien reissende wölfe, von denen das volk, statt wie von hirten geweidet, nur gemordet und geschunden würde wie die kälber von den metzgern am osterabend; diese angeblichen hirten seien selbst mit ihren schafen über fünfhundert jahreirre gegangen. Weiter erscheinen in anklage und verteidigung die aussprüche: die messe sei bloss den messelesenden nützlich, aber sonst keinem lebenden oder verstorbenen, und: die für kirchenbauten (zunächst wol von St. Peter in Rom, dann etwa auch von St. Vinzenzen in Bern) gemachten aufnahmen (gelderhebungen durch ablassverkäufe?). seien ein schinden der gläubigen; der lobgesang, den man singe, wenn man die leute zum opfer schicke, sollte nach Brunners meinung ein wolfsgesang heissen; er, Brunner, habe seine ganze theologie aus diesem wolfsgesang gelernt. 1)

Bei dieser verhandlung, die am 29. august nachmittags im Barfüsserkloster bei offenen türen stattfand, war unter den zahlreichen zuhörern sicher auch der maler Niklaus Manuel anwesend. Ihm, der vor wenigen monaten bei Novara und Bicocca mitgekämpft und die niederlage in zornigem liede gerächt hatte, ihm konnte, zumal wenn er vor einem halben jahre das fastnachtsspiel Von papsts und Christi gegensatz hatte aufführen lassen, das schicksal des pfarrers von KleinHöchstetten nicht gleichgiltig sein, der so mutig den papst und die bischöfe und die einrichtung der totenmessen angriff,

1) Nach B. Haller (Zürcher original, erst hand eines copisten, von $E t$ an hand Hallers selbst): Item was wir vffnemen an der [bei Zehender den] kilchen büw fpricht er wir /chinden wnd fiprechend fi föllend har zi gan, fo neme man/s mit dem lobge/ang vff. meint er mit dem volfge/ang nemen wir's vff. Et addidit, vnd all fin Theology hab er gelert $v / s$ den wolfg/ang. Ebenso (doch ohne die beifügung, die Haller wol aus dem munde Brunners dem schreibertext beigegeben hat: Simler 1,471, anm. Wirz s. 406, anm.) bei Anshelm: das mi dem wolfg/ang seiner originalhs. (n. ausg. 4, 473, anm.) ist wol schreibfehler (doch hat Scheurer s. 155: in dem Lobge/ang, meint Er mit dem Wolffefang; danach Kuhn a.a.o. s. 257: in den Lobge(ang). 
dessen vorgänger bereits gegen die gebete für die in Italien gefallenen geeifert hatte. Und wir erkennen den eindruck dieser stunde in Manuels grösserem stücke wider, das sich wol eben damals $\mathrm{zu}$ formen begann. Da begegnen uns nicht bloss die von Brunner gebrauchten allgemeinen schlagworte der zeit wider, wie die vom papst als dem wahren antichrist1) (1029. 1060. 1632; dazu bei Burg s. 46,6-9 und in den drucken vor v. 49 Papst, Entchristelo) oder vom schinden und fressen der schafe, die der papst und der bischof weiden sollten (135 ff. 1026 ff. 1244. 1319. 1360): es kehren auch individuelle ausdrücke wider, die wenigstens der maler Manuel damals am 29. august 1522 zuerst gehört oder doch zuerst mit nachhaltigem eindruck gehört hat. Seit mehr als fünfhundert jahren seien die priester mit ihren zuhörern irre gegangen und hätten diese betrogen, so hatte Brunner laut der anklagerede des decans gepredigt (man hatte das dann zu der behauptung verdreht, seit vier- bis fünfhundert jahren sei niemand selig geworden) - nicht viel zu sechshundert jahren fehle es, dass man den römischen ablass gelöst habe, so lässt Manuel einen seiner bauern klagen (1250 ff.). Der lobgesang, den die priester sängen, wenn sie die gläubigen für die kirchenbauten opfern liessen, sollte ein wolfsgesang heissen, so lautete eine andere eingeklagte rede Brunners - es fehle gar viel dazu, so schilt bei Manuel der edelmann (728 ff.), dass die geistlichen seine kinder, deren erbe sie verzehren, in den himmel brächten mit dem wolfsgesang, den sie sängen. Dieser ausdruck stammt allerdings aus dem titel einer pseudonymen schrift Vadians von 1521, worin das grosse geschrei, das der papst und die päpstler über seine würde verführen, so benannt wird ${ }^{2}$ ): die anwendung des wortes auf den gesang

1). Bei Zwingli mehrfach: Stähelin, H. Zwingli 1, 251. 297. Vgl. Schade, Satiren ( $\nabla$. j. 1525) 184, 22. 191, 12. 14.

2) Die schrift 'Das wolfsgesang' ist zur erklärung der rede Brunners zuerst beigezogen bei G.J.Kuhn in Trechsels Beiträgen z. Gesch. d. schweiz.reform. kirche 2, 137-140, wornach Studer im Bern. taschenb. 1885, s. 233 ff. Sie ist gedruckt bei $O$. Schade, Satiren und pasquille aus der reformationszeit 3, 1-35. Als eine 'Vadianische flugschrift', etwa mitte 1521 bei Adam Petri in Basel unter dem namen Judas Nazarei (-Vadian) erschienen, haben sie erst Eduard.Kück und Alfred Goetze (Beitr. 28, 236 ff., 1903) erkannt. Aus dem biblischen bilde der zuckenden (= reissenden) wölfe und 
bei der lösung des ablasses hat der Berner maler mit dem Berner pfarrer gemein, und diese anwendung musste in Bern besondern eindruck machen, wo vor vier jahren der chronist Anshelm über das 'wölfli', den chorherrn Lupulus, gespottet hatte, der mit dem füchslein Samson die schafe und gänse durch die ablasspredigt zu berücken suché. ${ }^{1}$ )

Die versammlung vom 29. august scheint sich der tragweite dieser verhandlung voll bewusst gewesen zu sein: Brunner dankte ${ }^{2}$ ) gleich eingangs gott, dass er ihn gewürdigt, unsern herrn Christum zu verteidigen, und als auf seine verantwortung die gegner stumm blieben, rief der vorsitzende Sebastian vom Stein dem decan mit ironischer anspielung auf das verhör Jesu, Joh. 18, 22, das wort Respondete pontifici!3) zu. Einem mann wie Manuel konnte die bedeutung des handels nicht entgehen, und das wort Brunners: die weihungen der bischöfe seien fastnachtsspiel und affenspiel und diese liessen ihre larven und fastnachtbutzen in der welt herumlaufen,

der wölfe im schafskleid (Schade 4, 30. 34, 22. 19, 28. 10, 36. 21,14), das auch Manuel in unserem stücke geläutig ist (143 f. 1046 roubuwölfen zän, 1745 bluitswolf, vgl. 1030 bliitshünd) und das er auch in seiner wappen- und figurenscheibe mit der umschrift Inweindig sind sie rei/sende Wölf angewant zu haben scheint (Scheurer, Maus. 2, 231), ist hier das des wolfsgesangs (Schade 16,36. 31,31), wolfsgeschreis $(15,26.25,12)$, wolfsgetöns $(24,11)$ oder wolfstons $(25,1)$ entwickelt und auf dem titel auch zeichnerisch ausgeführt (Schade 221. Studer 233), aber nirgends mit anwendung auf den für spendung von opfern in der kirche erhobenen gesang. Dagegen kann die ironische bemerkung Brunners, er habe seine ganze theologie aus dem wolfsgesang gelernt, recht wol auf das so betitelte büchlein Vadians gehen. - Eine berührung Manuels mit Vadian ist auch der ausdruck von der römischen kiste, dem schatz der römischen kirche: 1313. 1597; vgl. Vadian bei Schade 11, 16 zi Chrifto oder kiften.

1) Anshelm 4, 261.

2) Laut eigenhändiger beifügung Hallers zu seinem bericht: Et addidit, Ich dank ouch gott, das es miv darzi komen ift, das ich hïtt vff difen tag fol vifern lieben herren Criftum Jefum ver/prechen.

3) Nicht Antwortet doch, ihr Püpstler!, wie Wirz $(4,410)$ und Kuhn (263) nach dem willkürlichen Respondete pontificii des gedruckten Simler 480, sowie nach der abschrift im hsl. Simler übersetzen. Hallers eigenhändige bemerkung in seinem bericht, wo von dem allerdings ursprünglich geschriebenen Re/pondete portificii die zwei letzten buchstaben gestrichen sind, sowie Scheurer gaben das richtige. - Christus und Pilatus in unserem stücke $240 \mathrm{f}$. $1323 \mathrm{ff}$. 
um die menschen zum narren zu halten, konnten wol den satiriker in ihm neu anregen, der bereits in dem kleineren spiel die päpstliche klerisei als wild fasnachtbutzen bezeichnet und in dem grössern sie abermals, und nun sprechend, als zerrbilder der wahren kirche auftreten lässt.

Als Jörg Brunner, vom rate beschützt, ruhig auf seiner pfründe blieb und im folgenden jahr bei gelegenheit einer wallfahrt derer von Worb nach Klein-Höchstetten den kirchherrn Peter Wüstener einen ketzer und volksverführer nannte, hob der rat, bei dem Wüstener klagte, die beiderseitig ergangenen beleidigungen gegeneinander auf, 15. juni 1523.1) Sollte der name Kilianus Wüietrich, den der noch in der Hamburger hs. unseres spiels (vor 1788) einfach als cardinal bezeichnete päpstler im druck vom mai 1524 führt, eine ironische anspielung auf den streitbaren pfarrer Wüstener sein? Auch der decan (vor 231) könnte zu ehren von Brunners gegner, den Münsinger decan, nachträglich den namen Sebastian Schinddenburen erhalten haben. - Jedenfalls aber dürfen wir die reformatorischen gedanken, die der Brunner-handel von 1522 in Bern zum tagesgespräche machte, in einzelnen stellen unseres stückes, wie von der 500jährigen verführung des volkes und vom wolfsgesang, widerfinden.

Ebenfalls im laufe des jahres 1522 nun ward in schweizerischen und Berner landen eine besondere reformfrage brennend, wovon im Brunner-handel und auch in dem kleineren stücke Manuels noch gar nicht die rede ist: die frage der priesterehe.

Ulrich Zwingli hatte zu anfang des jahres seine gewissensehe mit Anna Reinhart geschlossen. Erst zwei jahre darauf konnte er sie öffentlich machen; vorerst aber richtete er mit zehn andern geistlichen an seinen bischof zu Constanz die berühmte bittschrift vom 2. juli um aufhebung des cölibatszwanges und widerholte dieses begehren am 13. juli in einer ausführlicheren deutschen zuschrift an die eidgenössischen stände. Hier wird bereits das cölibatsgebot als geldquelle der bischöfe verdächtigt, die für absolutionen von dessen über-

1) Stürler 1,103 f., Mentag Viti et Mö̈esti, zugleich mit dem ersten reformationsmandat, das allein das evangelium und die ler Gottes zu predigen befahl, ebda. $101 \mathrm{ff}$. Anshelm 5, 22 ff. 
tretern jährlich je 2, 3 oder 4 gulden bezögen, was im jahr eine grosse summe ausmache ${ }^{1}$ ): es gibt speck in die ro/swurst. ${ }^{2}$ ) Manuel lässt im grösseren spiel den By/sdschăff oder Fry/sdschăff den papst preisen, der den pfaffen die ehe verboten hat, sodass sich jetzt die laien über die unkeuschheit der geistlichen ärgern (156-170):

Was lyt mir dran? es bringt mir gelt.

Ich lon ims nach: warumm das nit?

So er mir vier rinfch guldy gitt

Alle jar, fo fich ich durch die finger ...

Fünffzehen hundert? ${ }^{3}$ ) guldy bringtz ain jar,

Das gelt kompt von pfaffenhiriren har;

Soltind pfaffen eewiber han ${ }^{4}$ ),

Es wurd uns nịt fpeck in d'prătwürst gen. ${ }^{5}$ )

Aehnlich sagt weiterhin die pfaffenmetze (291-298), ihr herr müsse dafürr, dass sie miteinander leben dürften, dem bischof jetzt jährlich vier gute rheinische gulden darlegen, und wenn sie ein kind gebäre, so habe der bischof wider seinen nutzen davon; sie habe ihm nun in zehn jahren mehr als fünfzig rheinische gulden bar eingebracht. Und der caplan (316-330) beklagt sich über die laien, die den geistlichen aus Paulus die notwendigkeit, eheweiber zu nehmen, beweisen wollen, sintemal nicht jeder die gnade habe, keusch zu bleiben. Auf 7 stellen des Paulus, sowie auf Matthäus 19 stützt auch Zwingli die berechtigung zur ehe für die priester, die sich nicht enthalten können (1. Cor. 7,8) oder denen die gabe der reinigkeit nicht verliehen ist. ${ }^{6}$ )

1) Zwinglis werke von Sehuler und Schulthess 1, 39.

2) Ebda. 47. In der lateinischen bittschrift, ebda. 1, 17-25, fèlen diese ausführungen.

3) Druck: Zwei tusend.

4) Druck: nen (ursprünglicher).

s) In gleichem sinn, aber nicht mit bezug auf die unkeuschheit der geistlichen, sagt der papst 774 es gibt nit speck. in die rüeben!

6) Ebenfalls in einer Zwinglischen schrift von 1522, der im august im kloster Oetenbach gehaltenen und unterm 6. september im druck erschienen predigt 'Von der klarheit des wortes gottes', wird der weltliche aufzug der geistlichen fürsten ganz ähnlich geschildert wie in unserm spiel $74 \mathrm{ff} .753 \mathrm{ff} .942 \mathrm{ff}$. $1388 \mathrm{ff}$. $1762 \mathrm{ff}$. und wie im kleinern $63 \mathrm{ff}$.: (Schuler und Schulthess 1, 72) Sy mögend jn [Christum] ouch nit hören vor jrem pracht der pferden, der diencren, der mu/ik, und Io triumphe; ebenda erscheint 
Bald darauf hatte sich auch die eidgenössische tagsatzung und Bern mit der frage der priesterehe zu befassen. Dass Johannes Haller schon im september 1521 sich nach Amsoldingen eine frau geholt, die er in Zürich öffentlich zur kirche geführt, war ihm noch hingegangen, da er sich den schutz des schultheissen dafür hatte zusichern lassen. ${ }^{2}$ ) Aber im sommer 1522 erklärte der pfarrer Hans Urban Wy Is von Fislisbach in der grafschaft Baden, also in einer der Gemeinen herschaften auf der kanzel unter anderem: er habe eine 'tochter' zur ehe genommen und werde sich, falls den priestern die ehe gestattet würde, öffentlich verheiraten. Der bischof von Constanz verlangte am 1. juli, um seine geistlichen untertanen im gehorsam zu behalten, den beistand der tagsatzung. Diese liess sich durch die fürsprache verschiedener geistlicher und die erlegung einer bürgschaft vorerst noch abhalten, den

das damalige geflügelte wort von den hohen pferden, worauf die grossen herren reiten ( $v$ gl. Schade, Satiren 182,17; in der Schweiz - Neftenbach 1525 -- : Egli, Actensammlung 808. Jahrb. f. Schw.-gesch. 9, 272), auf die geistlichen fürsten angewant: $\operatorname{Er}$ [Christus] mag uf die hohen ro/s nit ufhin ge/chryen, wie dies in unserm stück 646 (Vnd rittend doch fo hohe pferdt, vgl. 75 Ich rit allmal mit tusend pferden, Ein cardinal mit zwei drï hundert, und 406 Herr apt, ir vitend mit zwölf pferden, Hamb. hs. 20 pferden), und im kleineren 65 (Mit so grossen mechtigen hochen rossen, wofür in der Hamburger hs. in der scenarischen bemerkung in harne/ch vnd hochen pferden geritten) ebenfalls geschieht. - In den 'Schlussreden' Zwinglis vom 19. januar 1513 sodann erscheint die bezeichnung der mönche als verböggete (vermummte, verlarvte) mast/üw (Schuler und Sch. 1, 324); mestsüw u. dgl. heissen sie auch in unserm stück 371. 375. 456. 720. - In dem flugblatt, das $Z$ wingli über die botschaft papst Adrians (ende nov. 1522) an den reichstag zu Nürnberg erliess, sagt er in bezug auf den vom papst betriebenen Türkenzug: das wirksamste wäre, wẹnn er die bischöfe und cardinäle sieben mal des tages, $d$.h. ohne unterlass, die maụern und steinernen herzen der Türken mit dem posaunenschall des evangeliums umwandeln hiesse (Schuler und Sch. 3, 81): evangelisch zu handeln und die päpstlichen rechte zu vernichten, wäre der rechte Türkenzug, sagt bei uns Manuel 1903-1907. - Andererseits ward damals (1523? Eidg. abschiede 4, 1a, 368) auf katholischer seite gegen Zürich als gegen den Türken, den man jetzt in nächster nähe habe, gepredigt. - Nicht berührt ist in unserem stücke der Zürcher fastenstreit vom frühjahr 1522, der Zwinglis erste druckschrift hervorrief, nicht mehr "berührt der streit um messe und bilder von der octoberdisputation 1523.

1) Scheurer a.a.o. 2, 410. Kuhn a.a. o. s. 390. 
priester nach Constanz auszuliefern. 1) Inzwischen wurden Zwinglis bittschriften für die priesterehe allgemein bekannt; die tagsatzung beriet den fall am 3. und am 23. november, und übergab den pfarrer wegen lästerung der mutter gottes und der heiligen, sowie wegen übertretung des cölibats dem bischof zur bestrafung; Anshelm bemerkt - wie es scheint misbilligend - von Bern sei ritter Bastian zum Stein dabei gewesen. WyIs war noch während der Zürcher disputation vom 29. januar 1523, wo sich Faber mit der bekehrung des gefangenen brüstete, zu Constanz und später zu Gottlieben in haft; in Zürich höhnte nach schluss des gespräehs der bürgermeister Röist gegen Faber: 'das schwert, damit der pfarrer von Fislisbach zu Constanz erstochen ist, will nicht herfür.' Wol in die zeit der auslieferung des Wyls selbst geht die rede zurück, die uns Bullinger aus dem rolksmunde aufbewahrt zu haben scheint, wenn er zu diesem ersten fall einer verfolgung des evangeliums durch die eidgenossen die bemerkung macht, diese verfolgung sei geschehen $v / s$ antragen vnd vffitifften der geiftlichen: welche zu allen zyten Chriftum Pilato vnd Herodi fiirltellend.

Jedenfalls stützt sich Manuel auch seinerseits auf eine damalige gremeine rede, die auf den fall vom nov. 1522 ganz besonders gut passte, wenn er seinen decan sagen lässt, das evangelium sei schon zu lebzeiten Christi den pfaffen feindhich gewesen:

Darumb ward er Pilato geben,

Das er wider die priester was.")

1) Die rerschiedenen nachrichten und darstellungen (Eidg. abschiede 4, 1 a, 247-250. Anshel m 4, 469. 5, 18. Bullinger 1, 79f Hottinger, Helv. k-g. 3, 103. $111 \mathrm{f}$. Wirz, Helr. k.-g. 4, 1, 314-320) lassen rexschiedene datiernngen der bez. eiuzelnen verhandlungen rom sommer $1522 \mathrm{zu}$; jedenfalls aber war die sacbe seit anfang juli eine öffentliche geworden. - Dass dieser Hans Urban WY $\mathrm{W}$ 's ron Fislisbach, später weber und dann wider prädicant 20 Eglisau, Stein a.Rh. und a. o., nicht identisch ist mit Urban WJIs, sehulmeister zu Bischofszell wnd zu Bern, der 1553 die sprüche zu MIanuels taten$\tan z$ malte und mindestens teilweise rerfasste (A. Flori in Berner taschenb. auf 1901, 8. 139. $146 \mathrm{ff}$.), haben neverdings E. Egli und A. Fluri festgestellt: Archir des hist. rereins $r$. Bern (1902) 16, $540 \mathrm{f}$.

2) Die stelle fehlt sammt deu zwei vorhexgehenden rersen (239-242) in der Hamburger hs., ist also vielleicht erst nach der auffubrang hinzugekownen. 
Und wenn im herbst des folgenden jahres die reformfreunde Wyttenbach, Meyer und Haller wegen ihrer am 'schwätzrad' des inselklosters für die verehelichung der nonnen getanen reden mit einer blossen verwarnung davonkamen ${ }^{1}$ ); wenn einen monat später frau Anshelm für die bei ihrer verhängnisvollen baderede (oben s. 95 f.) nebenbei gemachte bemerkung, die priesterehe sei rechtmässig, weil Maria von priesterlichem stamme entsprossen sei, nur eine milde strafe erhielt ${ }^{2}$ ): so haben wir hier widerum bereits die freien ansichten über den cölibatszwang, wie wir sie in Manuels grösserem stück ausgesprochen sehen, wie sie aber im frühjahr 1522, vor der bittschrift Zwinglis und dem Wyis-handel, noch kaum auf die allgemeine billigung eines Berner fastnachtsspielpublicums hätten rechnen können und wie sie auch nach 1523 eine zeitlang weniger opportun waren, da trotz der bittschrift des capitels von Büren 1524 in den reformfragen, namentlich derjenigen über die priesterehe, eine rückströmung eintrat.

Im laufe des jahres 1522 ist endlich zu Bern eine reformatorische streitschrift entstanden, die sich so vielfach mit dem grössern spiel Manuels berührt, dass eine beeinflussung und zwar des ungelehrten verfassers durch das gelehrte werk oder dessen urheber, zum mindesten eine ungefähr gleichzeitige abfassung, durchaus angenommen werden muss.

Am 2. mai 1522, kurz nach erscheinen von Zwinglis erster druckschrift (Von erkiesen und freiheit der speisen) erliess der bischof von Constanz einen hirtenbrief, worin er klagte, dass zu derselben zeit, da die Türken über die christenheit herfielen, unchristliche lehren, die noch durch den verstorbenen papst Leo verdamint worden seien, von gelehrten und ungelehrten aufgebracht und allerorten besprochen würden. Der brief, der jeden sonn- und feiertag von den kanzeln verlesen werden sollte, erschien lateinisch und deutsch und fiel in dieser gestalt auch dem doctor Sebastian Meyer und den andern freunden Zwinglis zu Bern in die hände. Sie verfassten eine widerlegung, die satz für satz den äusserungen des bischofs ihre eigenen ansichten gegenüberstellte. Nachdem inzwischen Zwingli sich wegen der priestèrehe an den bischof und an

1) Anshelm 5, $25 \mathrm{f}$.

2) Ebda. $26 \mathrm{f}$. 
die eidgenossen gewant und mit jenem im Archeteles (22. aug.) sich auseinandergesetzt hatte, wollten auch die Berner mit ihrer kritik nicht zurückhalten. Meyer schickte das manuscript, auf dem er bereits einen erdichteten druckort angegeben, unterm 11. november an Zwingli mit der bitte, es durchzusehen, zu verbessern und womöglich in Zürich, jedoch, damit man den druckort nicht errate, mit noch unbekannten lettern drucken zu lassen. Das büchlein kam dann, wie es scheint, zu Basel heraus mit angabe eines druckorts Hohenstein. 1) Wir heben seine hauptgedanken hervor und vergleichen in den anmerkungen die besonders übereinstimmenden stellen von Manuels grösserem spièle.

Die hohen geistlichen, sagen gleich zu anfang die Berner freunde, gäben schweres ärgernis durch das weltliche leben, das sie mit kriegen, jagen und allerlei mutwillen führten. ${ }^{2}$ ) Nun erhöben sie neuerdings ablassgelder, angeblich um den Türken von Italien abzutreiben ${ }^{3}$ ), den sie ruhig den könig von Ungarn hätten bedrängen lassen.4) Möge man doch die durch ablass und tausenderlei schindereien ${ }^{5}$ ) gesammelten gelder, die kriegerischen bischöfe und pfaffen, die reichen abteien für den Türkenkrieg brauchen!6) Der papst treibe heidnisches gepränge ${ }^{7}$ ); die concilien ${ }^{8}$ ) und die bischöfe seien nicht vom heiligen geist, sondern von Aristoteles, Thomas, Scotus ${ }^{9}$ ) regiert. Leute, die diese studiert und auf der hohen schule zu Huttwil gelernt hätten, gölten jetzt als

1) Vgl. Hottinger, K.-g. 3, 88; ausführlicher Wirz, K.-g. 4, 1, 260-287. Kuhn s. 100-112. Der brief Meyers an Zwingli abschriftlich bei Simler S. mscr. 7 unterm 11. nov. 1522, woselbst bd. 7 das schriftchen selbst eingeheftet ist: Ernftiche Ermanung des Fridens ... Hugonis von Landenberg ... mitt Schöner v/slegung vnd erklärung ... nüwlich v/sgangen; am schluss: Gedruckt zu Hohensteyn, durch Hanns Fürwitzig, wozu die neuere hsl. bemerkung: (zu Zürich bey Fro/chauer).

2) Manuel v. 123-130.

3) 929 ff. 932 ff. 985 ff.

5) S. oben s. 98.

๑) $\mathbf{9 3 4} \mathrm{ff}$.

7) $1468 \mathrm{f}$.

4) $964 \mathrm{f}$.

9) $273 \mathrm{ff}$. Wir hand ins bap/ts rechte gle/en

Vnd Areftotiles wefen

Thomas Scotus vnd ander mer.

1900 Des ward der Ariftotiles hoch gebrifen. 
gelehrte ${ }^{1}$ ); ablass, messen, sacramente würden verkauft, als ob sie dem herrn Christus abgekauft worden wären ${ }^{2}$ ); mit terminieren ${ }^{3}$ ), jahrzeiten, vermächtnissen ${ }^{4}$ ) werde der gemeine mann geplagt. Das ärgernis, das die hurerei der priester gebe, habe der bischof auf deren beschwerde nicht nur nicht abgestellt durch gestattung der priesterehe, sondern die strafe für ein pfaffenkind von viers) auf fünf gulden erhöht, sodass er jetzt von jährlich 1500 pfaffenkindern seines bistums, statt 6000, 7500 gulden einnehme. Auch die concubinen müssten ihm jährlich abgekauft werden, sogar von solchen, die sich keine hielten. Mit recht nenne man solche bischöfe hurenwirte ${ }^{6}$ ); aber alle hurenwirte im ganzen bistum zusammen nähmen nicht so viel hurengeld ein wie er. ${ }^{7}$ ) - Der papst, der sich nachfolger Petri nenne, aber die gläubigen nötige, ihm das, was Christus mit seinem blut erkauft, täglich neu abzukaufens), sei der wahre antichrist. ${ }^{9}$ ) Fünfhundert jahre lang sei man unter seiner tyrannei gewesen ${ }^{10}$ ); aber 1500 jahre seien viel länger als 500 und also das evangelium viel älter als des papstes satzungen. ${ }^{11}$ )

1) 785 ff. $824 \mathrm{ff}$. Huttwil ist eines der kleinsten landstädtchen im Berner gebiet. 2) $1374 \mathrm{f}$.

s) $437 \mathrm{ff}$.

1) $345 \mathrm{f}$.

5) 158. 292: 4 gulden als busse für eine concubine, wozu noch die für pfaffenkinder hinzukommt: $160 \mathrm{f}$. $294 \mathrm{f}$. Von einer neuerlichen erhöhung der letztern busse (im bistum Constanz) ist allerdings bei Manuel (der im bistum Lausanne lebte) noch nicht die rede.

6) $171 \mathrm{f}: \quad$ Alzo bin ich ain fur/t v̄̄ gai/tlicher hirt Ia frylich zi gìtem tüt/ch ain hürē wirt.

Bei Schade, Satiren 189, 25 ff. (v.j. 1525) nennt der (wirkliche) hurenwirt den bi/s/chaf (ich solt jagen fri/s/chaf) ebenfalls hirrenjeger, nit be/ser deñ ein hurrenwirt, mein lands hirenwirt.

7) $301 \mathrm{ff}$. Doch gwan min hiren wirt nit fo vil An vns alle | das ich glöben wil

8) $1374 f$. Als ich dem bifchoff han muiffen geben.

9) S. oben s. 99; besonders nachdrücklich in der frühern form, Burg 46, 5-9, wo Petrus die apostelscene mit diesem wort beschliesst (auf Bächt. 1761 folgend): Dar by wend wirs beliben lon

Es mag die lenge nit befton

Wie wol er der alle' häyligeft gheiffé ift

So hiefler billicher der widerCrift.

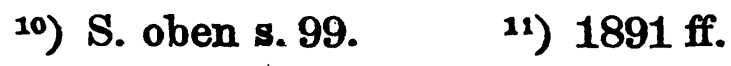


Aller ablass komme von Rom her und doch höre diese quelle nie auf $z u$ fliessen ${ }^{1}$ ); der papst sei ja ein gott auf erden ${ }^{2}$ ) und könne so lange und so viel ablass schaffen als er wolle. Die bischöfe und hohen herren möchten es schliesslich nicht übel nehmen, dass der verfasser ihre ansprüche bekämpfe, die teuflischer hochmut seien und von dem geringsten bauer, dem kleinsten kind als unbiblisch entkräftet werden könnten. ${ }^{3}$ )

Diese abfertigung eines hirtenbriefes, der im grössern teil des Berner landes allsonntäglich verlesen ward, während an den andern teil - so an Bern selbst - ein gleichlautender hirtenbrief von Lausanne aus ergieng ${ }^{5}$ ), erschien wol erst gegen ende 1522 im druck; aber sie war die erste kundgebung der reformationsfreunde in Bern und die zusammenfassung ihrer beschwerden gegen die misbräuche des papsttums. Eine ebensolche zusammenfassung war, bereits in den augen der zeitgenossen, das giössere spiel Manuels, während sich das kleinere im wesentlichen mit einer scenischen gegenüberstellung des weltlichen und kriegerischen papstes und des armen und demütigen gottessohnes begnügte. In dem grössern spiel finden wir dieselben gedanken und teilweise dieselben ausdrücke, die in dem reformatorischen Bern unter dem eindruck der Zwinglischen bittschriften, des Brunner- und des Wyis-handels in der zweiten hälfte des jahres 1522 umgiengen und damals von Sebastian Meyer und seinen freunden in ihrem commentar schriftlich zusammengefasst wurden; wir finden ausserdem in diesem spiel die belagerung von Rhodus vom spätjàhr 1522 als kernpunkt des ganzen verwendet. ${ }^{6}$ )

1) $1230 \mathrm{ff}$. $1250 \mathrm{ff} \cdot$ Zum wortlaut des commentars vgl. auch Freidank 148, 4 ff. 151, 23 alles schatzes vlüzze gânt ze Rôme u.s.w.

2) 842 .

3) Die bauernscene $1110 \mathrm{ff}$. In dem unterm 17. sept. 1522 gedruckten widmungsbrief $\mathrm{Z}$ winglis an seine brïder in Toggenburg preist er diese, dass sie dem frommen geschlecht der bauern und arbeiter treu bleiben, und mahnt sie, nicht pfaffentand für gottes wort zu halten. Schuler und Sch. 1, 84. 87.

4) Wirz 4, 1, 260.

5) Wirz a. a. o. s. 287. Die stadt Bern gehörte zum bistum Lausanne, das land rechts von der Aare zu Constanz.

6) Die ausserdem noch berührten auswärtigen ereignisse dürften bei näherer untersuchung ebenfalls belege für unsere datierung liefern. Allerdings ist von dem tode cardinal Schinners, sept. 1522, ebensowenig wie von 
Es ist zweifellos: nach allen diesen ereignissen und eindrücken, auf die fastnacht 1523 hin, nicht aber auf die fastnacht 1522, hat Niklaus Manuel das spiel von den totenfressern und den misbräuchen des papsttums geschrieben. Die Zürcher ausgabe von 1524 hat das grössere spiel falsch datiert und Anshelm hat sich im j. 1535 dadurch täuschen lassen.

Und es fehlt schliesslich auch nicht ganz an spuren davon, dass man es in Bern und ausserhalb besser wusste als es Froschauer im j. 1524 und als es Anshelm im j. 1535 gewusst hat.

Zunächst enthält die Berner jahrrechnung von 1523 (erste jahreshälfte) folgende angabe ${ }^{1}$ ): Denen, (o das Spill in der

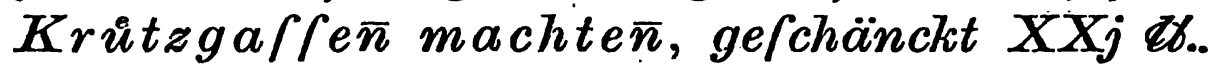

Die rechnungen von 1522 erwähnen von fastnachtsspielen nichts. Deswegen kann damals ein kleineres spiel - und zwar ebenfalls an der kreuzgasse, wo Manuels kleineres spiel tatsächlich aufgeführt ward - gleichwol gehalten worden sein; aber sicher ist eines dort im $j .1523$ gehalten worden, und zwar nur eines, das in der rechnung einfach als 'das spiel in der kreuzgasse' bezeichnet werden konnte und das, vermutlich eben weil es ein grösseres war, von der regierung mit geld unterstützt oder belohnt ward. ${ }^{2}$ ) Und dieses wird eben

dem des papstes Leo $X$. , 1. dec. 1521, notiz genommen; vielmehr erscheint die kriegspolitik des papstes und insbesondere des cardinals (vigl. $1458 \mathrm{ff}$. 1788 ff.) als etwas gegebenes und unveränderliches, wie bereits im 'Traum', der ebenfalls nach der wahl Hadrians VI. (9. jan. 1522, der aber erst im

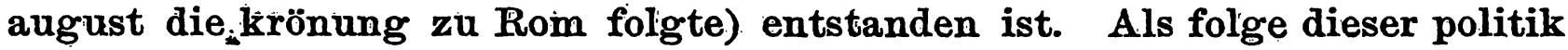
ergibt sich die ablehnung der hilfe gegen die Türken, die ja in der tat nicht zu stande kam, wenngleich Hadrian im nov. 1522 auch die Schweizer daran mahnte, worauf $Z$ wingli ganz ähnlich kritisch antwortete wie Manuel und sein doctor Schüchnit, oben s. 103, anm.

1) Auf die mich herr A. Fluri freundlichst aufmerksam gemacht hat; vgl. desselben Kulturgeschichtliche mitteilungen aus den Bernischen staatsrechnungen des 16.jh.'s, Bern 1894, s. 39.

2) Vor 1523 wurden (nach Fluri a.a.o.) obrigkeitliche spenden für aufführungen zu teil: 1506 (I) Denen die das Spil der zwölff planeten gemacht hannd, an da/felb zi Stür $10 \mathrm{Pfd}$. (wahrscheinlich bei derselben gelegenheit, da man dem oheim Niklaus Manuels, Hannsen Appenteker, 2 pfd. bezahlte umb vier tortschen [fackeln] als die von Zürich in der va/snacht hie warenn); 1514 (I) Den ge/ellen, fo das Spil an der Crützga/fen hatten 20 Pfd.; 1515 (I) Den gefellen, fo das Spill an der Crützga/fen 
unser grüsseres spiel gewesen sein, mindestens in seinen hauptbestandteilon, wozu neben der totenfresserscene vor allem die Rhodiser- und musterungsscone (und zwar in der ordnung der Hamb. hs.) mit gehorten.

In katholischen streitschriften wird 60 jahre spater noch bestimmt behauptet, ein reformatorisches Borner spiel, oder deren zwei, seien in den drucken betrüglicherweise vordatiert worden, als ob sie noch in der katholischen zeit Berns gehalten worden whren. Es geschieht dies durch den Luzexner stadtschreiber Rennwart Cysat in einer antwort der katholischen orte auf den vortrag der vier ' $/$ winglischen stetten' vom november 1585, und sodann in einem memorial für die tagsatzung zu Baden vom 9. murz 1586.') Zwar liess Cysat in der letzten redaction seiner antwort vom 22. januar 1586 die stelle von der vordatierung weg; aber etwas wahres war offenbar an dieser beschuldigung, die ein mann wie Cysat

hattenn $20 \mathrm{Pfd}$. und abormals Den kinaben, /o das Spill and der Criitegaffen machten o P/al.; 1516 (I) Denenen, to Spill [mohrore?] in dev Va/snacht machterin, ok kionen, tit 14 Pfal. 13 B. 4. ㄱ. - Nach 1523 begegnon (violleicht in folge dos rllcksolings, der bald nnch dom spiol von 1523 in roformatorischen dingen eintrat) sponden orst wider (nachdom 1531 ein spiel von hoidnischor und pipstlichor algubtterei, wio es scheint, ohuo solohe gohalten worden) 1584, 25. folrr., wo den 'lehrkuabeu' (studenton) zelurung und kosten firr oin spiel vom Vorlormon soln bezahlt werdon, und seither dns ganze juhrhundort durch, eine zeitlang fast jedes jahr, mit botrigen bis auf 100 und $200 \mathrm{pfd}$. - Ts schoint also das dem Mantiel zugoschriebeno 'Thlsli Trugdenkunbon', das lnut dor titelbomorkung zu herrenfastnacht 1580 in Bern wenjge wochen vor Mannols tod aufgefuhrt worden ist, nicht unterstiltzt worden zu soin, was violloicht nnch gogen soine verfassorscliaft spvicht; soin 'Ablasslerimer' (1525) lat wol nioht gospiolt wordon, soin 'gosprtich' 'Barbali' (1526) offenbur niolht zur auffuhrung bestimmt gewesen, obensowenig wio dio 'Trankheit der messo' (1528).

1) Blichtold oxdexi f. Burg s. 124 (vgl. Didg. absohiede 4, 2, 896 ff. 903. 905. 909. 919-040. $927 \mathrm{f}$.). Cysat erwithut die getoreckten und hochsehmulats-

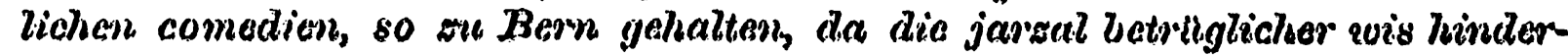
sich gestellt, als ob as Beschehen, devuilen sie nooh bi uns im waren catholischen glaulbon voreint voaren und im Momorial eim sehanttich schmachspil,

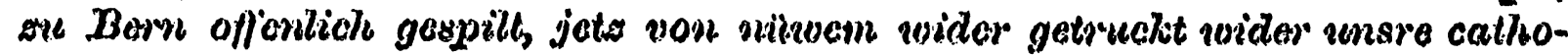
lisehe quav'd veligion und geistliche oberlicit. Stat im anfang, es sig im 1538. jar gaschiehan, so dooh Borm orst 0 jar tharnach abgefallen; findi abes sich, dass es harmach im 16.89. oder 1633. jar gesehehon. Vgl. Basler boitr. zux paterl. gesch. (1846) 8,00. 
nicht einfach aus der luft griff; nur war es sicher nicht eine vordatierung um 6 bis 10 jahre und anch keine vordatierung in betrüglicher absicht, sondern lediglich ein irrtum des Zürcher druckers ron 1524, der über die aufführungszeit der Berner spiele mangelhaft unterrichtet war, anch das grössere spiel wahrscheinlich in sehr zerrütteter form vor sich hatte.

In J.J.Simlers hsl. sammlnng von reformationsurkunden (nach Zehenders hsl. Kirchengeschichte 1, 37 f ${ }^{1}$ ) ist die aufführung unserer beiden spiele anf fastnacht 1523 angesetzt und wird das grössere als das andere (= zweite) an zweiter stelle aufgeführt.: ) Wir wissen nicht, woher Simler dieses datum hat, das mit dem vorhergehenden, von ihm nicht mit citierten satze Anshelms streitet, und für das er selbst an einer andern stelle seiner sammlung (S. mscr.6, einleitung zum

1) Nicht aber in der gedruckten 'Sammlung alter und neuer urkunden zur beleuchtung der kirchengeschichte, vornehmlich des Schweizer-landes von Johann Jakob Simlern' 1. 2, Zürich 1758, s. 463, anm., wo nach dem titel der ausgabe von 1524 and nach Anshelm die datierung 1522 beibehalten ist. Auch in der hsl. sammlung in der stadtbibliothek zu Zürich habe ich bei der erwähnung der Manuelschen spiele (s. unten s. 112, anm.1) sowie im febr. und märz 1523 die stelle umsonst gesucht und muss mich an Zehenders abschrift halten.

2) Nach Zehender, s. oben s. 97: 'Insonderheit hat er [Niklaus Manuel] das Evangelium beförderet, und das Papstthum verhasst gemacht, durch zwey Comedie-Spiel, offentlich an der Creüzgass annô 1523 auf Fassnacht gehalten, in welchen der Verfasser den Verfall der Kirchen, und dess damaligen geistlichen Standes lebendig abgeschildert und in Verse gebracht. I In dem ersten Spiel hat er vorgestellt den Himel weiten Unterscheid, so da ist zwischen dem Wesen und Leben Christi und seiner A posteln auf Erden, und zwischen der grossprächtigen Anfführung dess Papsts und seiner Clerisey, die doch Christi und seiner Jünger Nachfolger und Statthalter sein wollen.

In dem Andern Spiel stellet er vor die Leiche-Begengniss eines reichen Mannes, über dessen Tod die Clerisej höchstens erfreüet war, als welche unter dem Vorwand der Religion durch einen selbst erdichteten Gottesdienst den Weltlichen suchen Haab und Guth abzuschwäzen, damit sie desto reichlicher im Überfluss, Wollusten und Lastern leben möchten.

Lasset uns vom Erfolg dieser Spielen und dardurch geschafften Frucht hier beysezen, was Valerius Anshelmus, der Aug- und Ohrenzeug dieser Spielen gewesen, davon aufgezeichnet hat. Durch diese wunderliche ... [es folgt die Anshelm-stelle, unten s. 117]"... dieser Spielen |a|

|a| Die vollkō̄ene Geschicht samt den Versen kan nachgele[se]n werden Scheurerus in Vita Nicolai Manuel.' 
handel G. Brunners, im druck s. 462 f.), das herkömmliche datum 1522 giebt ${ }^{1}$; aber irgendwoher muss diese abweichende datierung rühren. Sein abschreiber Zehender verweist nebenbei auf Scheurer, der freilich auch die herkömmliche jahreszahl und die herkömmliche reihenfolge bietet, jedoch mit einer bemerkenswerten abweichung.

Bei Scheurer nämlich (Berner. mausoleum 1740, s. oben), der anfangs die datierung Anshelms widergibt, findet sich im verlaufe seines werkes ein eigentümliches schwanken in bezug auf die priorität der beiden spiele. Im leben Sebastian Meyers, Maus. 1, 145 f., sagt' er von den 'zweyen Spielen und teutschen Gedichten Manuels: 'Das Erste auf Herren Falsnacht 1522 war betitelt Der Todten-Fresser'; 'Das andere Spiel wurd gehalten 8. Tag hernach, an der Bauren, oder alten Fast-nacht', worauf wie beim ersten spiel eine inhaltsangabe und sodann ein auszug folgt. Dagegen im Leben Niklaus Manuels 2; 231, wo er, offenbar nach Anshelm, wider von den ' $\mathrm{z}$ weyen offentlich zu Bern an der Creutzgals gehaltenen Comedi spiehlen'. spricht, 'welche von Ihres Zwecks und inhaltenden Materi wegen die Evangelische Freyheits Spiehle genennet werden mögen', gibt er (nach dem Berner druck von 1540) einen auszug 'aus dem anderen Spiel, so auf der Zweyten, nemlich der Herren Fafsnacht, gespielt wurde, der Todten Fresser geheifsen'2) (die hervorhebungen stehen im druck). Die 'herrenfastnacht' ist aus

1) 'Niclaus Manuel, ... der durch seine Fastnachtspiele, so er in dem benañten $1522 \mathrm{Jahr}$ aufführen lassen, den Pabst und ganze Priestersch aft zum ofentlichen Gelächter vorgestelt hat.' Ebenso in der anmerkung, wo, offenbar als quelle der datierung, der titel der Zürcher ausgabe von 1525, 3. jan. widergegeben wird.

2) In den Antiquitates Bernenses des Berner staatsarchivs; die nur eine von Scheurers hand geschriebene vorarbeit zu dessen Mausoleum sind (Rochholz, Eidg. liederchronik s. 377 citiert sie als 'Nachrichten von dem leben Junkers J.o h. Niklaus Manuel'; es steht: aber bloss Jkr. N. M.), findet sich noch keine andeutung dieses schwankens; die spiele sind dort 2,59104 vollständig nach der ausgabe von 1540 ('aus einer copie, die aus einem authentischen mit der stadt Bern ehren wappen gezeichneten exemplar gemacht worden') abgeschrieben. - Im Mausoleum macht Scheurer zu dem kleinern spiele die bemerkung: "Es hinterliesse diese Vorstellung einen so allgemeinen Eindruck, dass noch heut zu Tag viele Merkmahle in den Fensteren hin und her im Land davon anzutreffen sind.' Ueber die sechs 
Anshelm beibehalten, aber - unrichtig - als zweite fastnacht bezeichnet, weil Scheurer jetzt anderswoher (vgl. Simler und Zehender) das grössere stück als das 'andere', d.h. spätere spiel kannte. Diesen widerspruch und diesen irrtum Scheurers hat sein bearbeiter Kuhn (1828) a.a.o. s. 285, anm. bemerkt, gibt aber unbeirrt Anshelms datierung wider. Ebenso Wirz in der Helv. kirchengeschichte (1814) $(4,2,399)$. Beide entnehmen ihre proben den texten bei Scheurer. Woher Leu, Helv. lex. (1757) die - geschichtlich durchaus unmögliche angabe hat, 'Der totenfresser' sei 1519 geschrieben worden, sagt er nicht; für die aufführung folgt er - wie es scheint für beide spiele - der herkömmlichen datierung ${ }^{1}$ ), die auch in der literaturgeschichte seit den ausgaben Max Schneckenburgers (1836), C. Grüneisens (1837), Jakob Bächtolds (1878) unbestritten gilt.

Wir glauben nachgewiesen zu haben, dass die datierung märz 1522 für die aufführung von Niklaus Manuels grösserem spiel 'Die totenfresser' oder 'Vom papst und seiner priesterschaft' unhaltbar ist und dass dessen abfassung frühestens im spätjahr 1522, dessen aufführung frühestens in der fastnacht 1523, dessen herrichtung und interpolation für den ersten druck vom mai 1524 frühestens ende 1523 stattgefunden hat.

Anlass und stoff lieferten die reformatorischen ereignisse in Bern und der eidgenossenschaft vom sommer 1522: die händel wegen Georg Brunners, wegen der priesterehe und wegen des Constanzer hirtenbriefs, und sodann namentlich die belagerung von Rhodus mitte august bis ende december 1522. Die auf diesen ereignissen aufgebaute erste fassung des stückes ist, bez. war in der (auf Berner papier von 1521-1523 geschriebenen) Hamburger hs. erhalten. ${ }^{2}$ )

im j: 1840 durch den brand der kirche von Boltigen untergegangenen fensterscheiben mit der bez. darstellung s. Bächt. CxxxviII, anm.

1) Leu, Allgemeines Helvetịsches, Eydgenöl'sisches, Oder Schẅeitzerisches Lexicon 12,492: [Manuel] hat schon A. 1519. ein Lust-Spiel, das unter dem Namen des Todten-Fressers wider den Pabst, und das andere A. 1522. von dem Gegen-Satz zwischen Christo und dem Pabst, aufgesezt, welche von der Jugend vorgestellt und hernach A. 1525 und 1540 gedruckt worden.

2) Sie scheint im zusammenhang mit der aufführung von 1523 entstanden zu sein: einige fehler dürften auf verhörung des gesprochenen oder dictierten wortes zurückgehen: rülis und stübis $>$ fǜbas und fürbas, 
Nach der aufführung hinzugekommen ist noch in Bern gegen ende 1523 oder $\mathrm{zu}$ anfang 1524 die (in der Hamb. hs. noch nicht erscheinende) person und rede des quästionierers 437-494 mit der anspielung auf den handel der frau Anshelm, der am 25. nov. 1523 und am 6. jan. 1524 vor den rat kam, und mit dem hinweis auf übelstände, die im dec. 1522 in der flugschriftenliteratur bekämpft und sodann auch zu Bern im nov. 1524 durch ratsbeschluss abgestellt werden. ${ }^{1}$ )

Für den ersten druck, mai 1524, ist sodann noch, wahrscheinlich erst in Zürich, hinzugefügt worden die person und rede des Johannes Fabler, der die gegenkritik seiner kritik vom 10. märz 1523 über die erste Zürcher disputation, das im laufe desselben jahres in Zürich erschienene 'Gyrenrupfen', klagend erwähnt. Der interpolator, der an dieser stelle den zusammenhang unverständig zerstört hät, ist auch für die sinnlose hineinschiebung eines teils der musterungsscene zwischen die bauern- und die apostelscene, sowie namentlich auch für die falsche datierung der aufführung im titel verantwortlich zu machen.

Auf dem machwerk dieses Zürcher bearbeiters von 1524, um das sich Manuel und die Berner offenbar sehr wenig bekümmert haben ${ }^{2}$, , beruhen alle weitern Zürcher und ander-

und besonders 1760 kein früemess $>$ kein übels! wogegen an andern stellen doch wol verlesung vorliegt: 566 buren $>$ bleren. Häufiger sind jedoch die fälle, wo die hs. gegenüber den drucken die ursprünglicheren worte und verse und die alten, später (in Bern oder eher in Zürich) aus sprachlichen gründen abgeänderten reime bietet: letzteres z. b. 884 f. 1464 f. 1854, während z. b. 309 f. 358 (zu spitze hölzli vgl. Schw: id. bei holz) der umgekehrte fall vorliegen dürfte, dass dem schreiber der ursprüngliche reim nicht mundgerecht war. Die ganze frage bedarf noch der untersuchung, die durch stud. E. Roggen begonnen ist:

1) S. oben s. 96 und anm.

2) Vgl. besonders oben s. 872. 902. 93 f. Von der meinung Bächtolds (s. CXXXI), dass die 'überarbeitung zum druck' von 1524 'unbedingt von Manuel allein herrühre' (ähnlich Singer a.a.o. s.11), dürfte also für unser stück ziemlich das gegenteil wahr sein. Dass er 'die idee zu den beiden fastnachtsspielen mit gleichstrebenden freunden beraten hat', ist vielleicht gegenüber Anshelms ausdruck fürnemlich durch ... N. M. gedichtet (vgl. oben s. 82, anm.), der doch wol schon nach der wortstellung nichts anderes bedeuten kann als 'vornehmlich, hauptsächlich, grösstenteils' (nicht aber: in vorzüg:licher weise, 'meisterlich', wie Singer a.a.o. s.11 erklärt), noch 
weitigen ausgaben, sowie die Berner ausgabe von 1540 und vorher schon die falsche datierung bei Anshelm.

Um den 1523 gespielten und nicht durch interpolationen entstellten text Manuels zu gewinnen, ist künftig nicht mehr einer der drucke, die uns bisher das spiel in zerrütteter und überarbeiteter gestalt geboten haben, sondern die Hamburger hs. von $1523 \mathrm{zu}$ grunde $\mathrm{zu}$ legen und nur, wo sie offenbare fehler bietet und wo sie ihre grosse lücke hat, aus den drucken zu ergänzen. Es bleibt dabei noch zu untersuchen, ob die bauernscene in der hs. nur in folge der lücke fehlt, in die sie hineinfallen würde, oder aber, ob sie in der urform nicht gestanden hat; ob sie vielleicht die einleitung $\mathrm{zu}$ dem ablassumzug am aschermittwoch gebildet hat, wovon uns Anshelm berichtet, und erst durch den druck in unser spiel hineingekommen ist. Ebenso bleibt für das kleinere spiel Manuels die datierung einstweilen ungewiss. Entweder ist die angabe der aufführung zur bauernfastnacht 1522 festzuhalten - dann ist das kleine stück in abwesenheit des verfassers, der am 9. märz vor Mailand lag, aufgeführt worden und Anshelm hat im j. 1535, angesichts der datierung im druck und bei unklarer erinnerung, die aufführung oder die aufführungen von herrenfastnacht und aschermittwoch 1523 als diesem stück 1522 unmittelbar vorangegangen sich gedacht und damit ein hysteronproteron begangen, das wir richtig stellen müssen durch datierung des kleineren stücks auf 1522, des grösseren auf 1523. - Oder: auch das kleinere stück ist erst im jahre 1523 aufgeführt worden - dann hat sich, was nach den ereignissen von 1522/23 wol denkbar wäre, an das grosse zu herrenfastnacht mit regierungsunterstützung gehaltene spiel am aschermittwoch der ablassumzug und an der bauernfastnacht der doppelaufzug von papst und Christus angeschlossen, und Anshelm hat auf die autorität des druckes hin die aufführung der beiden ihm vorliegenden bühnenstücke sowie den aschermittwochs-

etwas zu wenig gesagt, wenigstens was unser grösseres spiel betrifft. Das stück war eine gemeinsame angelegenheit der spielenden 'burgerssöhne', von denen vermutlich dieser oder jener $z \mathfrak{u}$ dem ursprünglich vielleicht einheitlicheren werke Manuels etwas hinzufügte, was dann auch in die handschriften hineinkam; der druck in Vürich dagegen war rein geschäftliche unternehmung des dortigen druckers. 
umzug, der nur in seiner erinnerung lebte, von fastnacht 1523 auf fastnacht 1522 zurückgeschoben. Wir halten letztere möglichkeit für die wahrscheinlichere. So wie so hat sich Anshelm täuschen lassen, als er - übrigens erst im anschluss an die ereignisse vom august und september 1522! - die aufführung der Totenfresser in die fastnacht 1522 setzte: die aufführung wenigstens unseres grösseren stückes fällt endgiltig in das jahr 1523.

Mit dieser spätern datierung, wird auch die anregung Manuels durch den dialog 'Die totenfresser' von Pamphilus Gengenbach, der nach Gödeke zwischen 1509 und 1522 in Basel druckte und dichtete, wahrscheinlicher: die mehrfachen übereinstimmungen beider dichtungen sowie der titel, den die Manuels nach Anshelm führte, sind als benutzung der älteren dichtung durch die jüngere $z u$ erklären. Doch bleibt das verhältnis der beiden stücke noch genàuer zu untèrsuchen. Ebènso ist eine noch eingehendere vergleichung zwischen dem Hamburger und den gedruckten texten unserer Manuelspiele zum zwecke ihrer verbesserten neuausgabe anzustellen.

Einstweilen ist für unsern Berner dichter in unserer untersuchung zweierlei gewonnen:

1) Durch die beseitigung späterer zusätze und umstellungen auf grund einer sichern datierung ist die ordnung und der zusammenhang seiner ursprünglichen dichtung widerhergestellt worden. Sie erscheint als eine immer noch formlose, aber an verschiedenen stellen nun weit besser geordnete dramatische satire eines dichters, der nur unter der fülle seines stoffes leidet, aber ihn wol zu gruppieren weiss.

2) Durch die einordnung der dichtung in die zeitereignisse wird die tat, die Manuel und seine freunde mit der aufführung der 'Totenfresser' vollbracht haben, verständlicher und verdienstlicher. Sie geht nicht mehr - was man ihr bisher mit verwunderung ${ }^{1}$ ) als vorzug angerechnet hat - den ersten reformatorischen ereignissen in Bern voran, sondern sie fasst, wie dies dem laien allein zustund, die durch diese ereignisse im volke erzeugte gesinnung in glücklicher volksmässiger form zusammen und greift damit im richtigsten augenblick und mit

1) So besonders Kuhn a.a.o. s. 297. 
bestem erfolg in die bewegung der geister ein. Es bleibt bei der neuen datierung unseres spiels erst recht das urteil Anshelms über die bedeutung von Manuels dramatischen arbeiten bestehen:

'Durch diese farbenreichen schaustellungen (wunderliche anschowungen), deren gleichen bisher (als gotteslästerlich) nie erhört gewesen, ward viel volkes bewegt, christliche freiheit und päpstliche knechtschaft überdenkend zu unterscheiden.' 1 )

1) Anshelm hs. 3, 1281, z. 11-19 Durch difs wunderliche vnd vor nic, als | gotzle/terliche, gedachte an/chownugen | wardd ein gro/s volck bewegt krift|liche fryheit, vnd bab/tliche knecht|/chaft zi bedencken, vnd ze vnderfcheiden. I Es ift ouch jn dem Euangelifchen han|del kum ein bíchle fo dick getruckt, I vnd fo wyt gebracht worden, als difer Spilen.

BERN, 20. märz 1903. FERDINAND VETTER. 